\title{
Andrographis paniculata (Burm. f.) Wall. ex Nees: A Review of Ethnobotany, Phytochemistry, and Pharmacology
}

\author{
Md. Sanower Hossain, ${ }^{1}$ Zannat Urbi, ${ }^{1}$ Abubakar Sule, ${ }^{2}$ and K. M. Hafizur Rahman ${ }^{3}$ \\ ${ }^{1}$ Department of Biotechnology, Kulliyyah of Science, International Islamic University Malaysia, 25200 Kuantan, Pahang, Malaysia \\ ${ }^{2}$ Department of Microbiology, School of Applied Sciences, Federal Polytechnic Institute, Nasarawa, Nigeria \\ ${ }^{3}$ Department of Basic Medical Sciences, Kulliyyah of Pharmacy, International Islamic University Malaysia, 25200 Kuantan, \\ Pahang, Malaysia
}

Correspondence should be addressed to Md. Sanower Hossain; mshossainbge@gmail.com

Received 30 July 2014; Revised 25 September 2014; Accepted 25 September 2014; Published 25 December 2014

Academic Editor: Thomas Efferth

Copyright ( $2014 \mathrm{Md}$. Sanower Hossain et al. This is an open access article distributed under the Creative Commons Attribution License, which permits unrestricted use, distribution, and reproduction in any medium, provided the original work is properly cited.

\begin{abstract}
As aboriginal sources of medications, medicinal plants are used from the ancient times. Andrographis paniculata is one of the highly used potential medicinal plants in the world. This plant is traditionally used for the treatment of common cold, diarrhoea, fever due to several infective cause, jaundice, as a health tonic for the liver and cardiovascular health, and as an antioxidant. It is also used to improve sexual dysfunctions and serve as a contraceptive. All parts of this plant are used to extract the active phytochemicals, but the compositions of phytoconstituents widely differ from one part to another and with place, season, and time of harvest. Our extensive data mining of the phytoconstituents revealed more than 55 ent-labdane diterpenoids, 30 flavonoids, 8 quinic acids, 4 xanthones, and 5 rare noriridoids. In this review, we selected only those compounds that pharmacology has already reported. Finally we focused on around 46 compounds for further discussion. We also discussed ethnobotany of this plant briefly. Recommendations addressing extraction process, tissue culture, and adventitious rooting techniques and propagation under abiotic stress conditions for improvement of phytoconstituents are discussed concisely in this paper. Further study areas on pharmacology are also proposed where needed.
\end{abstract}

\section{Introduction}

Medicinal plant is an integral part of human life to combat the sufferings from the dawn of civilization [1]. It is estimated that more than 80,000 of total plant species have been identified and used as medicinal plants around the world [2]. Among these plants, more than 1300 plant species have been used traditionally in Malaysia where the knowledge is being passed down from generation to generation [3]. The indigenous medicinal plants and plant-derived drugs are the potential source of alternative medicine and are extensively used to treat various health ailments [4]. Use of the medicinal plants is a core component at primary health care level due to availability, acceptability, compatibility, and affordability. Dependency on these medicinal plants varies from country to country. It is estimated that about $75-80 \%$ of people of developing countries and about $25 \%$ of people of developed countries depend either directly or indirectly on medicinal plants for the first line of treatment $[3,5]$. Therefore, people are encouraging indigenous production and processing of these medicinal plants to use in different cultures and religion for the treatment of various diseases. Moreover, importance and uses of medicinal plants are also stated in different religious books (i.e., the Holy Qur'an, the Bible). About 19 medicinal plants and 176 medicinal plants are mentioned in the Holy Qur'an [6] and the Holy Bible [7], respectively.

Andrographis paniculata (Burm. f.) Wall. ex Nees (AP) is an important medicinal plant and widely used around the world. It belongs to the family Acanthaceae. AP is used as a traditional herbal medicine in Bangladesh, China, Hong Kong, India, Pakistan, Philippines, Malaysia, Indonesia, and Thailand $[8,9]$ and is ethnobotanically used for the treatment of snake bite, bug bite, diabetes, dysentery, fever, and malaria [3]. In the Unani and Ayurvedic medicines, AP 
is one of the mostly used medicinal plants [8]. In recent times, commercial preparations of this plant extracts are also used in certain countries. However, the preparations yet need to be standardized for their better efficacy. The aerial part of AP is most commonly used; its extracts contain diterpenoids, diterpene glycosides, lactones, flavonoids, and flavonoid glycosides. Whole plant leaves and roots are also used as a folklore remedy for different diseases in Asia and Europe $[8,10]$. AP has been reported to have a broad range of pharmacological effects including anticancer [1118], antidiarrheal $[19,20]$, antihepatitis [21, 22], anti-HIV [23], antihyperglycemic [24-27], anti-inflammatory [28-32], antimicrobial, antimalarial [33, 34], antioxidant [35-37], cardiovascular [38, 39], cytotoxic [23], hepatoprotective [4052], immunostimulatory [53-57], and sexual dysfunctions [58].

Since the AP is used for the treatment of many diseases in traditional medicinal systems, its intended benefits need to be evaluated critically. Therefore, this paper reviews the ethnobotany, some agronomic techniques, isolation and characterization of phytoconstituents, and pharmacological properties of AP. Additionally, chemical properties, biological functions, and possible mode of actions of phytoconstituents are also entertained. The literature searches were conducted in worldwide accepted scientific database PubMed (http://www .ncbi.nlm.nih.gov/pubmed), ScienceDirect (http://www.sciencedirect.com/), Scopus (http://www.scopus.com/), Web of Science (http://webofknowledge.com/), Springer Link (http:// link.springer.com/), Wiley Online Library (http://onlinelibrary.wiley.com/), and advance search in Google scholar (http://scholar.google.com.my/), as well as recognized books, abstract, and some nonimpact, and nonindexed journals. The search strings used were "Andrographis paniculata" or "King of Bitters" or "Kalmegh" or "Hempedu bumi" or "Andrographolide." Further relevant papers were searched in the aforementioned databases from the list of references of all available papers. The authors went through more than 300 full papers and a total of 243 peer-reviewed papers focused on plant description, agronomic techniques, traditional uses, bioactive compound extraction, phytoconstituents, and pharmacology properties (such as common cold, anti-inflammatory, antihyperglycemic, hepatoprotective, antibacterial, antiviral, antiparasitic, anticancer, immunomodulatory, cardiovascular, antihyperlipidemic, sexual dysfunctions, contraceptive, safety, and toxicity effects) were selected for this review. We briefly discussed recent scientific findings and proposed some fields where further study is needed.

\section{Botany}

2.1. Origin and Distribution. A. paniculata is native to Taiwan, Mainland China, and India. It is also commonly found in the tropical and subtropical Asia, Southeast Asia, and some other countries including Cambodia, Caribbean islands, Indonesia, Laos, Malaysia, Myanmar, Sri Lanka, Thailand, and Vietnam [59-61]. This plant is also found in different phytogeographical and edaphic zones of China, America, West Indies, and Christmas Island [61].
TABLE 1: The morphology and physiology of A. paniculata $[10,62$, 63].

\begin{tabular}{|c|c|}
\hline Traits & Values/characteristics \\
\hline Plant height & $30-110 \mathrm{~cm}$ \\
\hline Stem & Dark green \\
\hline Length & $30-100 \mathrm{~cm}$ \\
\hline Diameter & $2-6 \mathrm{~mm}$ \\
\hline Shape & $\begin{array}{l}\text { Quadrangular with longitudinal furrows and } \\
\text { wings on the angles of the young parts, slightly } \\
\text { enlarged at the nodes }\end{array}$ \\
\hline Leaves & Glabrous \\
\hline Length & $2-12 \mathrm{~cm}$ \\
\hline Width & $1-3 \mathrm{~cm}$ \\
\hline Arrangement & Lanceolate \\
\hline Shape & Pinnate, acute apex, entire margin \\
\hline Flowers & White with rose-purple spots on the petals \\
\hline Size & $\begin{array}{l}\text { Small, in lax spreading axillary and terminal } \\
\text { racemes or panicles }\end{array}$ \\
\hline Seed & Capsules linear-oblong, acute at both ends \\
\hline Size & $1.9 \mathrm{~cm} \times 0.3 \mathrm{~cm}$ \\
\hline Color & Yellowish brown \\
\hline Shape & Subquadrate, numerous \\
\hline $\begin{array}{l}\text { Flowering and } \\
\text { fruiting }\end{array}$ & December to April \\
\hline
\end{tabular}

2.2. Plant Description. A. paniculata is an important medicinal plant of Andrographis genus. A total number of species of this genus varied in different reports, which comprises either $19[64,65], 28[59,66], 40[62,67]$, or $44[68]$ species. The exact numbers of species of Andrographis genus are not validated yet. Total number of chromosomes of AP is 25 and 50 in gametophytic [69] and sporophytic [70] count, respectively. In addition, genotypic differences are important considerations to find out high yielding germplasms.

A. paniculata is an annual, branched, erect, and herbaceous plant which grows in hedgerows throughout the plane lands, hill slopes, waste ground, farms, moist habitat, seashores, and roadsides. It also can be cultivated in garden. Moist shady places, forests, and wastelands are preferable for their well development $[59,71]$. The morphological and physiological data of AP are presented in Table 1 and Figure 1. This plant grows abundantly in Southern and Southeastern Asia including India, Java, Sri Lanka, Pakistan, and Indonesia, while it is cultivated in India, China, Thailand, Brunei, Indonesia, the West Indies such as Jamaica, Barbados, and Bahamas, Hong Kong, and the tropical areas in America and also in southwestern Nigeria $[10,71]$.

2.3. Taxonomic Hierarchy. Taxonomic hierarchy is as follows:

Domain: Eukaryota,

Kingdom: Plantae,

Subkingdom: Tracheobionta,

Superdivision: Spermatophyta, 


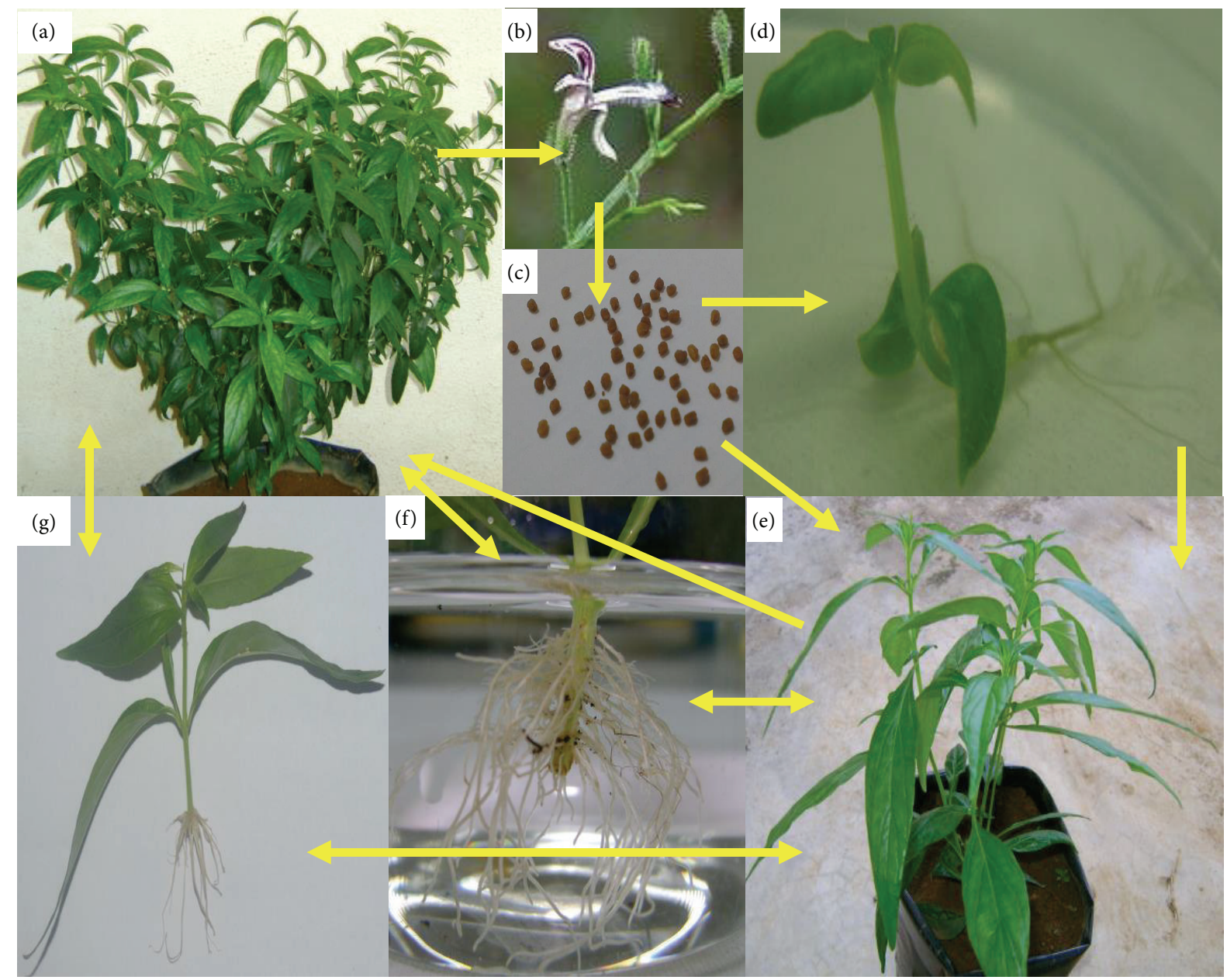

Figure 1: Morphology of Andrographis paniculata. (a) Mature A. paniculata in polybag stage, (b) flowering stage, (c) harvested seeds, (d) in vitro seedling, (e) young A. paniculata in polybag, (f) adventitious roots of A. paniculata, and (g) vegetative seedlings. Single direction of arrow indicates the developmental stages and both directions of arrow denote vegetative propagation of plant (Photographs are taken from M.S. Hossain's research work, except (b)).

Division: Angiosperma,

Class: Dicotyledonae,

Subclass: Gamopetalae,

Series: Bicarpellatae,

Order: Personales,

Family: Acanthaceae,

Subfamily: Acanthoideae,

Tribe: Justiciae,

Subtribe: Andrographideae,

Genus: Andrographis,

Species: A. paniculata (Burm. f.) Nees [71, 73, 74].

2.4. Vernacular Names. Generally, the tree is known as "King of Bitters" for its extremely bitter taste. In Malaysia, AP is traditionally known as "hempedu bumi" (bile of the earth). This plant has different names in different languages. The vernacular names of AP are presented in Table 2. In addition, local people easily recognize plant species with vernacular names instead of binomial names.

2.5. Agronomic Techniques. Plants conventionally grow via seed culture. Planting and harvesting time has influenced the yield of plant $[153,154]$. Usually, May to July is the recommended time for sowing AP seeds with a spacing of $30 \times 15 \mathrm{~cm}$ that resulted in a plant density of 222 thousands plants/ha and average biomass of $3 \mathrm{t} / \mathrm{ha}[155,156]$. However, seed dormancy is a major constrain in AP cultivation commercially $[157,158]$. Although hormonal media and hot water treatment have been suggested to overcome this problem [159, 160], this technique is not enough to meet the commercial quantities required due to variability among the seed-derived progenies and scanty and delayed rooting of seedlings [161, 162]. Therefore, nonconventional propagation methods such as plant tissue culture techniques are alternative methods to produce plenty of plantlets within a short time and improve phytochemical contents in AP. Tissue culture techniques have been applied for large scale propagation of AP [162-164]. 
TABLE 2: The vernacular names of $A$. paniculata $[10,71,75,76]$.

\begin{tabular}{|c|c|}
\hline Language & Name \\
\hline Arabic & Quasabhuva \\
\hline Assamese & Chiorta, Kalmegh \\
\hline Azerbaijani & Acılar Şahı, Acılar Xanı (khanı) \\
\hline Bengali & Kalmegh \\
\hline Burmese & Se-ga-gyi \\
\hline Chinese & Chuan Xin Lian \\
\hline English & The Creat, King of Bitters \\
\hline French & Chirette verte, Roi des amers \\
\hline Gujarati & Kariyatu \\
\hline Hindi & Kirayat, Kalpanath, \\
\hline Indonesian & Sambiroto, Sambiloto \\
\hline Japanese & Senshinren \\
\hline Kannada & Nelaberu \\
\hline Konkani & Vhadlem Kiratyem \\
\hline Lao & La-Sa-Bee \\
\hline Malay & Hempedu Bumi, Sambiloto \\
\hline Malayalam & Nelavepu, Kiriyattu \\
\hline Manipuri & Vubati \\
\hline Marathi & Oli-kiryata, Kalpa \\
\hline Mizo & Hnakhapui \\
\hline Oriya & Bhuinimba \\
\hline Panjabi & Chooraita \\
\hline Persian & Nain-e Havandi \\
\hline Philippines & Aluy, Lekha and Sinta \\
\hline Russian & Andrografis \\
\hline Sanskrit & Kalmegha, Bhunimba and Yavatikta \\
\hline Scandinavian & Green Chiratta \\
\hline Sinhalese & Hīn Kohomba or Heen Kohomba \\
\hline Spanish & Andrografis \\
\hline Tamil & Nilavembu \\
\hline Telugu & Nilavembu \\
\hline Thai & Fa-Talai-Jorn, Fah-talai-jon (jone) \\
\hline Turkish & Acılar Kralı, Acı Paşa, Acı Bey \\
\hline Urdu & Kalmegh, Kariyat, Mahatita \\
\hline Vietnamese & Xuyên Tâm Liên \\
\hline
\end{tabular}

Dandin and Murthy [164] reported that in vitro regenerated AP contains higher amount of andrographolide compared to the mother plants. Optimum production of andrographolide can be achieved in a short span by employing the suspension cultures of AP [165]. Plant tissue culture has also been successfully used to form new flavones from callus culture [166-168].

\section{Ethnobotanical Uses}

Ethnobotanically, the leaves and roots of AP have been used since centuries in Asia and Europe to cure the wide spectrum of health ailments. However, the whole plant is also used for certain limited purposes. Due to its "cold property" activity, it is recommended to be used to get rid of the body heat in fevers and to dispel toxins from the body. The plants are also recommended for the use in cases of leprosy, gonorrhea, scabies, boils, skin eruptions, and chronic and seasonal fever for its high "blood purifying" properties $[8,169]$. The overall traditional uses of AP in different traditional medicinal systems (TMS) or countries are pointed out in Table 3 . In addition, it is also widely used for medicinal purposes by the traditional practitioners, tribes, or community as a folklore remedies in different countries [9].

\section{Phytoconstituents}

The aerial parts of AP have been described for its innumerous use in the extraction of phytoconstituents; however, leaves, stems, roots, and whole plants have also been reported for phytochemicals with pharmacological activities. The compositions of phytochemicals widely differ in terms of the part used, geography, season, and time of harvesting. M. Sharma and R. Sharma [76] reported that the highest amount of andrographolide, a major bioactive compound of AP, was found in the sample harvested after 110 days of cultivation followed by that just before flowering stage (130 days). The bioactive compounds were extracted with different types of solvents such as methanol $(\mathrm{MeOH})$, ethanol $(\mathrm{EtOH})$, hexane, acetone, acetone-water, chloroform $\left(\mathrm{CHCl}_{3}\right)$, and dichloromethane from the whole plant, leaves, aerial parts, stems, and roots. Extraction procedure of bioactive compounds of AP from $\mathrm{MeOH}$ extracts, for example, is shown in Figure 2. In this extraction procedure, whole plant material of AP $(11.5 \mathrm{~kg})$ was shade dried, ground, extracted with methanol $(10 \mathrm{~L} \times 6)$ under reflux for $8 \mathrm{~h}$, and filtered to give residue. After filtration, three residues of the extract were found: (i) $\mathrm{CHCl}_{3}$ residue $\left(700 \mathrm{~g}\right.$ ), (ii) $\mathrm{H}_{2} \mathrm{O}$ soluble (1.5 kg), and (iii) $\mathrm{H}_{2} \mathrm{O}$ insoluble residue ( $\left.150 \mathrm{~g}\right)$. The residues were then chromatographed to get specific fractions. These fractions were further chromatographed and followed several procedures to identify specific compound (Figure 2). A total of 32 bioactive compounds with seven ent-labdane diterpenoids, twelve flavonoids, and two quinic acid derivatives have been isolated and characterized by this procedure. Previous phytochemical studies of AP have reported more than 55 ent-labdane diterpenoids, 30 flavonoids, 8 quinic acids, 4 xanthones $[132,150]$, and 5 noriridoids, namely, andrographidoids A, B, C, D, and E [170, 171].

Zhang et al. [172] reported 3 new ent-labdane diterpenoids, namely, 19-norandrographolides $\mathrm{A}, \mathrm{B}$, and $\mathrm{C}$ from the ethanol extracts of the aerial parts of AP. Their structures have been established by HRESIMS and NMR spectral data in combination with X-ray crystallographic analysis; thus the 19-norandrographolide-A was identified as 3-dehydro-14deoxy-19-norandrographolide. However, there is no report for pharmacological activity of these three compounds. The quinic acids were extracted only from the whole plants using the methanol solvents and they are functioning as an antiplatelet aggregator [72]. Recently, Arifullah et al. [141] demonstrated moderately potent antimicrobial and antioxidant activity of andrographolide and echiodinin extracted from acetone and methanol extracts of in vitro leaf callus of AP. Their structure elucidation was determined by electrospray ionization, MSD, NMR, and IR spectra. The yield 
Table 3: The ethnobotanical uses of A. paniculata.

\begin{tabular}{|c|c|c|}
\hline Country/TMS* & Traditional uses & Reference \\
\hline Ayurvedic & Fever, liver diseases, torpid liver, vitiligo & {$[62]$} \\
\hline Japan & Fever, common cold & {$[10]$} \\
\hline Malaysia & Diabetes, hypertension & {$[10,77]$} \\
\hline Scandinavian & Fever, common cold & {$[10]$} \\
\hline $\begin{array}{l}\text { Traditional } \\
\text { Bangladeshi medicine }\end{array}$ & $\begin{array}{l}\text { Acute diarrhea, anorexia, bloating with burning sensations in the chest, blood } \\
\text { purifier, common cold, constipation, cough, debility, diabetes, dysentery, edema, } \\
\text { emesis, fever, headache, helminthiasis, indigestion, intestinal worms, leucorrhea, } \\
\text { liver disorders, loss of appetite, low sperm count, lower urinary tract infections, } \\
\text { lung infections, malaria, mucus, pharyngotonsillitis, sexual and skin disorders, } \\
\text { splenomegaly, uncomplicated sinusitis, vertigo }\end{array}$ & {$[9]$} \\
\hline $\begin{array}{l}\text { Traditional Chinese } \\
\text { medicine }\end{array}$ & $\begin{array}{l}\text { Inflammation, fever, burn, carbuncle, cervical erosion, chicken pox, common cold, } \\
\text { cough with thick sputum, detoxicant, detumescent, diarrhea dispel toxins of the } \\
\text { body, dysentery, eczema, epidemic encephalitis B, fever, hepatitis, herpes zoster, } \\
\text { laryngitis, mumps, neonatal subcutaneous annular ulcer, neurodermatitis, pelvic } \\
\text { inflammation, pharyngitis, pharyngolaryngitis, pneumonia, respiratory infections, } \\
\text { snake bites, sores, suppurative otitis media, tonsillitis, vaginitis }\end{array}$ & {$[8,10]$} \\
\hline $\begin{array}{l}\text { Traditional Indian } \\
\text { medicine }\end{array}$ & $\begin{array}{l}\text { Diabetes, dysentery, enteritis, helminthiasis, herpes, peptic ulcer, skin infections } \\
\text { (topical use), snake-bites (topical use) }\end{array}$ & {$[10]$} \\
\hline $\begin{array}{l}\text { Traditional Thai } \\
\text { medicine }\end{array}$ & Fever, common cold, noninfectious diarrhea & {$[10]$} \\
\hline $\begin{array}{l}\text { Unani system of } \\
\text { medicine }\end{array}$ & $\begin{array}{l}\text { Anthelmintic, anti-inflammatory, antipyretic, aperient, astringent, boils, } \\
\text { carminative, chronic and seasonal fevers, convalescence after fevers, diuretic, } \\
\text { dysentery, dyspepsia associated with gaseous distension, emmenagogue, emollient, } \\
\text { gastric and liver tonic, general debility, gonorrhea, irregular bowel habits, leprosy, } \\
\text { loss of appetite, relieve griping, scabies, skin eruptions }\end{array}$ & {$[8]$} \\
\hline
\end{tabular}

of this compound was higher compared to the field plant. On the other hand, a novel flavonoid, 7, 8-dimethoxy-2'hydroxy-5-O- $\beta$-d-glucopyranosyloxyflavone, together with 15 known flavonoids was isolated from the aerial parts of AP. The structure was elucidated on the basis of chemical and spectroscopic analysis. Significant antiproliferative activity of these flavonoids against human leukaemia HL-60 cell was also investigated [142]. Dua et al. [143] investigated four xanthones (1,2-dihydroxy-6,8-dimethoxyxanthone; 1,8-dihydroxy-3,7-dimethoxyxanthone; 3,7,8-trimethoxy-1hydroxyxanthone; 4,8-dihydroxy-2,7-dimethoxyxanthone) from roots of AP using $\mathrm{CHCl}_{3}$ fraction and purity confirmed by HPLC. Xu et al. [171] isolated and established structure of 5 rare types of noriridoids with a known iridoid curvifloruside $\mathrm{F}$ from the ethanol extracts of roots. They also assayed antibacterial activity of these compounds, but none showed any inhibitory activity (MIC $>100 \mu \mathrm{g} / \mathrm{mL}$ ). In this review, we provided available information on around 46 isolated phytoconstituents of AP with structure, chemical properties, IUPAC name, reported pharmacological activities, mode of extraction, and parts used (Table 4).

\section{Potential Pharmacology}

Extensive use of AP in traditional medicinal system has proven its efficacy over the past three decades. Several researches including in vitro, in vivo (animal), and clinical (human) studies have confirmed various pharmacological activities of AP extracts and products. A wide range of pharmacological activities such as antiplatelet aggregation activity [72], immunomodulatory activity [57, 109-113, 139], and other myriad health benefits $[10,75,132]$ were observed among these researches. Andrographolide, a major entlabdane diterpenoid of AP, is the largest contributor of many pharmacological activities. Other ent-labdane diterpenoids (such as neoandrographolide and 14-deoxyandrographolide), flavonoids, quinic acids, and xanthones are also reported for their significant contributions. A few of the reported works on pharmacology are summarized below.

5.1. Effect on Common Cold. A. paniculata is commonly used for the prevention and treatment of common cold in several communities. A double-blind, placebo-controlled study of 61 adult patients suffering from common cold used Kan Jang tablets (made from A. paniculata dried extract) for 5 days. Within the treatment period, significant clinical improvement was observed on day 4 for $1200 \mathrm{mg}$ extract daily. Both groups showed significant reductions in clinical symptoms like shivering, sore throat, tiredness, muscular ache, rhinitis, sinus pains, and headache [173]. A placebocontrolled study was conducted in 1997 using Kan Jang tablets on 107 healthy students in a rural school as a dose of 2 tablets $(200 \mathrm{mg})$ per day for 3 months to evaluate its efficacy to prevent common cold. The common cold was successfully prevented by Kan Jang tablets with 2.1-fold higher prevention rate compared to the placebo group [174]. Similar successful 


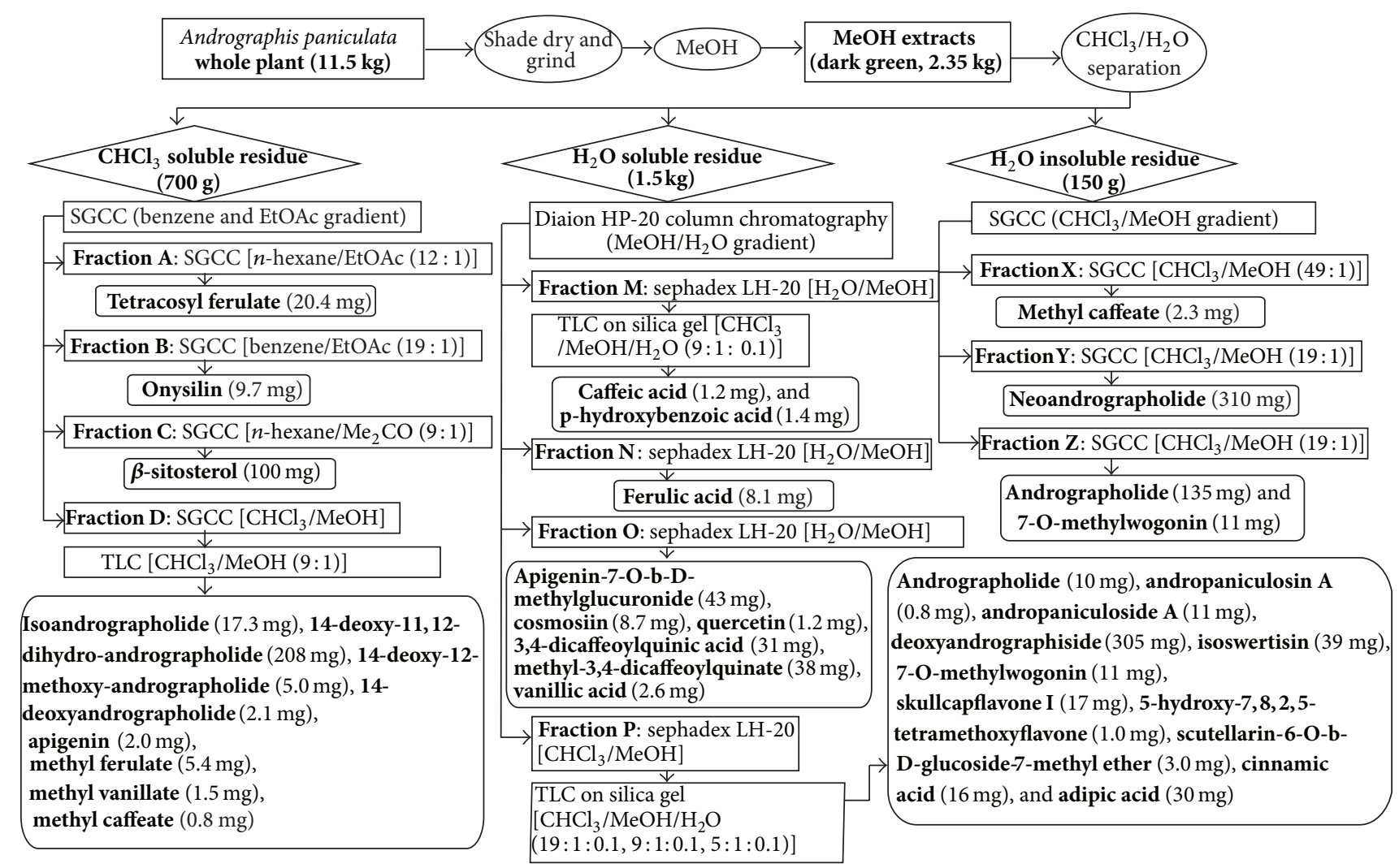

Figure 2: Extraction of pure compounds of A. paniculata from MeOH extracts. Yield of pure compounds is in bracket in mg. Their structures have been elucidated mainly by $1 \mathrm{D}$ and 2D NMR and MS spectroscopic methods. SGCC: silica gel column chromatography; TLC: thin layer chromatography, $\mathrm{MeOH}$ : methanol; EtOAc: ethyl acetate, $\mathrm{CHCl}_{3}$ : chloroform (adopted from [72]).

result was also demonstrated in another study including common cold with sinusitis in another place [175].

5.2. Anti-Inflammatory Effect. The anti-inflammatory activity of AP and its bioactive compounds (such as andrographolide and neoandrographolide) has been reported individually by many investigators [28-32, 95-100, 118, 119, 176]. AP extracts and andrographolide showed several antiinflammatory activities, such as inhibition of intercellular adhesion molecule-1 expression in monocytes activated by tumor necrosis factor- $\alpha$ [177], suppression of inducible nitric oxide synthetase (iNOS) in RAW264.7 [29], cyclooxygenase2 (COX-2) expression in neutrophils and microglial cells [95, 96], reduction of ERK1/2 phosphorylation in murine $\mathrm{T}$ cells [90] and IFN- $\gamma$, and IL-2 production $[57,90]$, and inhibition of TNF- $\alpha$ and GM-CSF induced by LPS [176]. In a study conducted by Hidalgo et al. [96], andrographolide was analyzed for the activation of NF- $\kappa \mathrm{B}$ induced by platelet-activating factor (PAF) and $\mathrm{N}$-formylmethionyl-leucyl-phenylalanine (fMLP) in HL-60 cells differentiated into neutrophils. NF$\kappa \mathrm{B}$ controls or contributes to the transcription of more than 200 genes that are involved in a variety of physiological and pathophysiological processes, particularly in immunity and inflammation. It is a critical regulator of cell differentiation, proliferation, and apoptosis and plays pivotal roles in the normal organ development and tumorigenesis [178]. However, the NF- $\kappa \mathrm{B}$ can be activated via the signal transduction pathways which are multiple and complex. It was a surprising achievement that andrographolide significantly inhibited the binding of NF- $\kappa$ B to DNA, which is the final step of $\mathrm{NF}-\kappa \mathrm{B}$ activation and it also decreased the expression of cyclooxygenase-2 (COX-2) by inhibiting the activation of $\mathrm{NF}-\kappa \mathrm{B}$ in endothelial cells stimulated by PAF [179] and in microglial cells induced by lipopolysaccharide (LPS) [95]. In addition, the kidney inflammation can also be recovered using andrographolide due to its ability to inhibit the NF- $\kappa \mathrm{B}$ activated by LPS in kidney [180].

Oral administration of andrographolide at a dose of $300 \mathrm{mg} / \mathrm{kg}$ daily had shown significant analgesic activity on acetic-induced writhing in mice and on the Randall-Selitto test in rats, but there was no effect on the hot plate test in mice [78]. Oral administration of andrographolide at 30, 100 , and $300 \mathrm{mg} / \mathrm{kg}$ also showed anti-inflammatory activity in different models in rats [181]. Iruretagoyena et al. [57] suggested that treatment with andrographolide at a daily dose equal to $4 \mathrm{mg} / \mathrm{kg}$ significantly reduced an inflammatory demyelinating disease of the central nervous system, autoimmune encephalitis by inhibiting $\mathrm{T}$ cells in mice. The balancing of proinflammatory and anti-inflammatory cytokines is the result of anti-inflammatory performance of andrographolide and regulation of Th1, Th2, and Th17 transcription factors. Andrographolide also increased GATA3 mRNA expression but decreased T-bet and ROR $\gamma \mathrm{t}$ mRNA expressions [182]. 


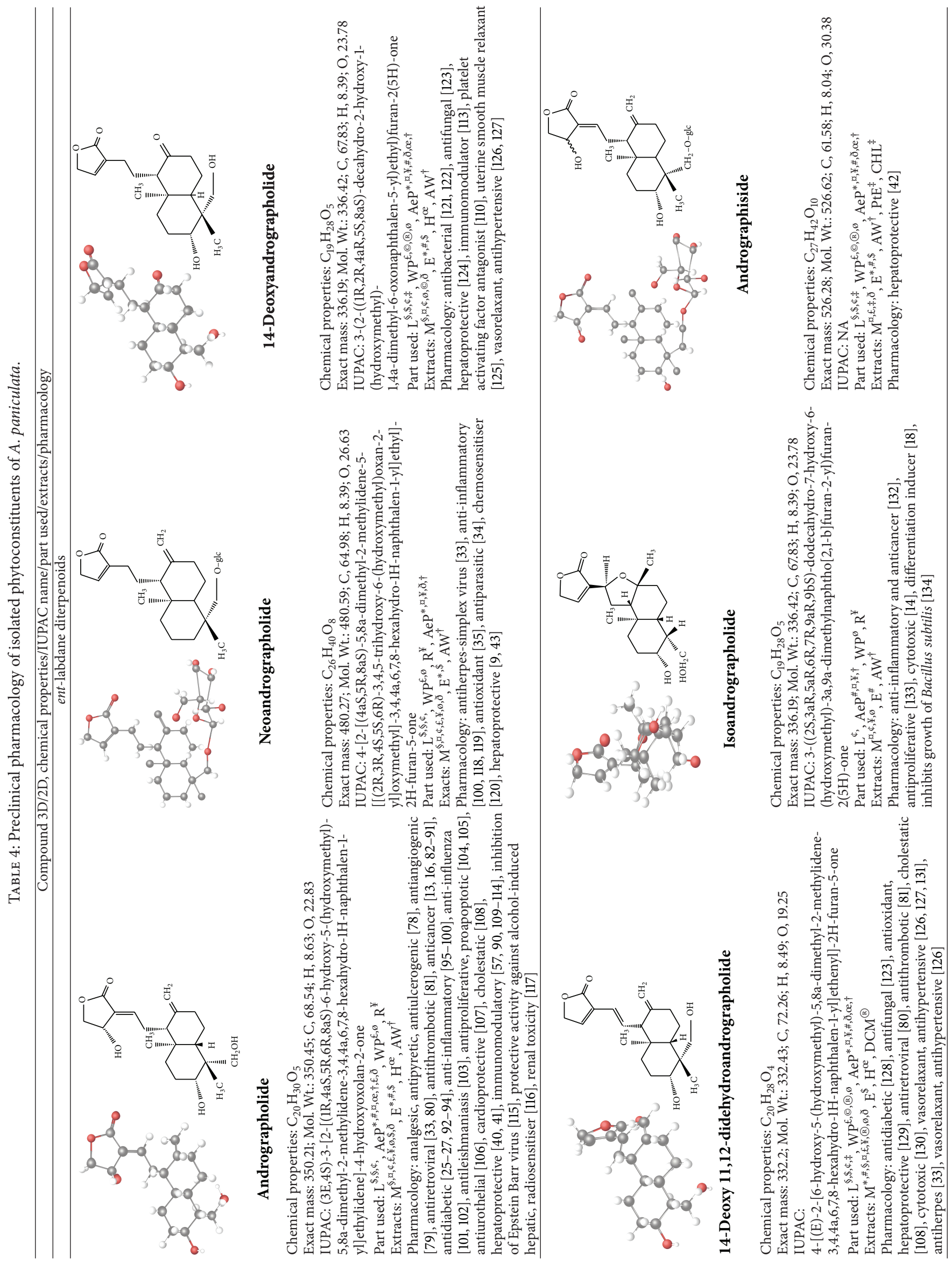




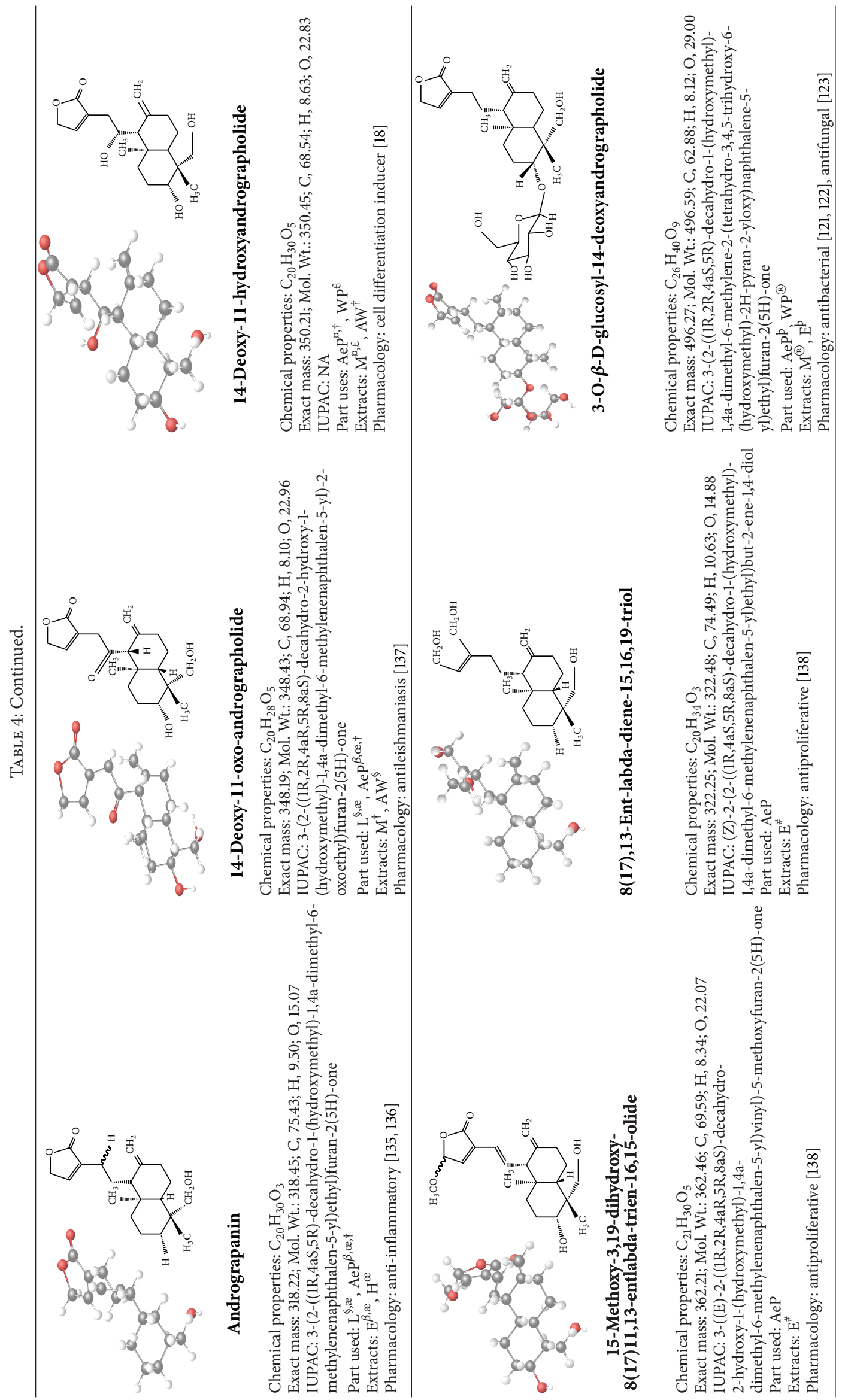




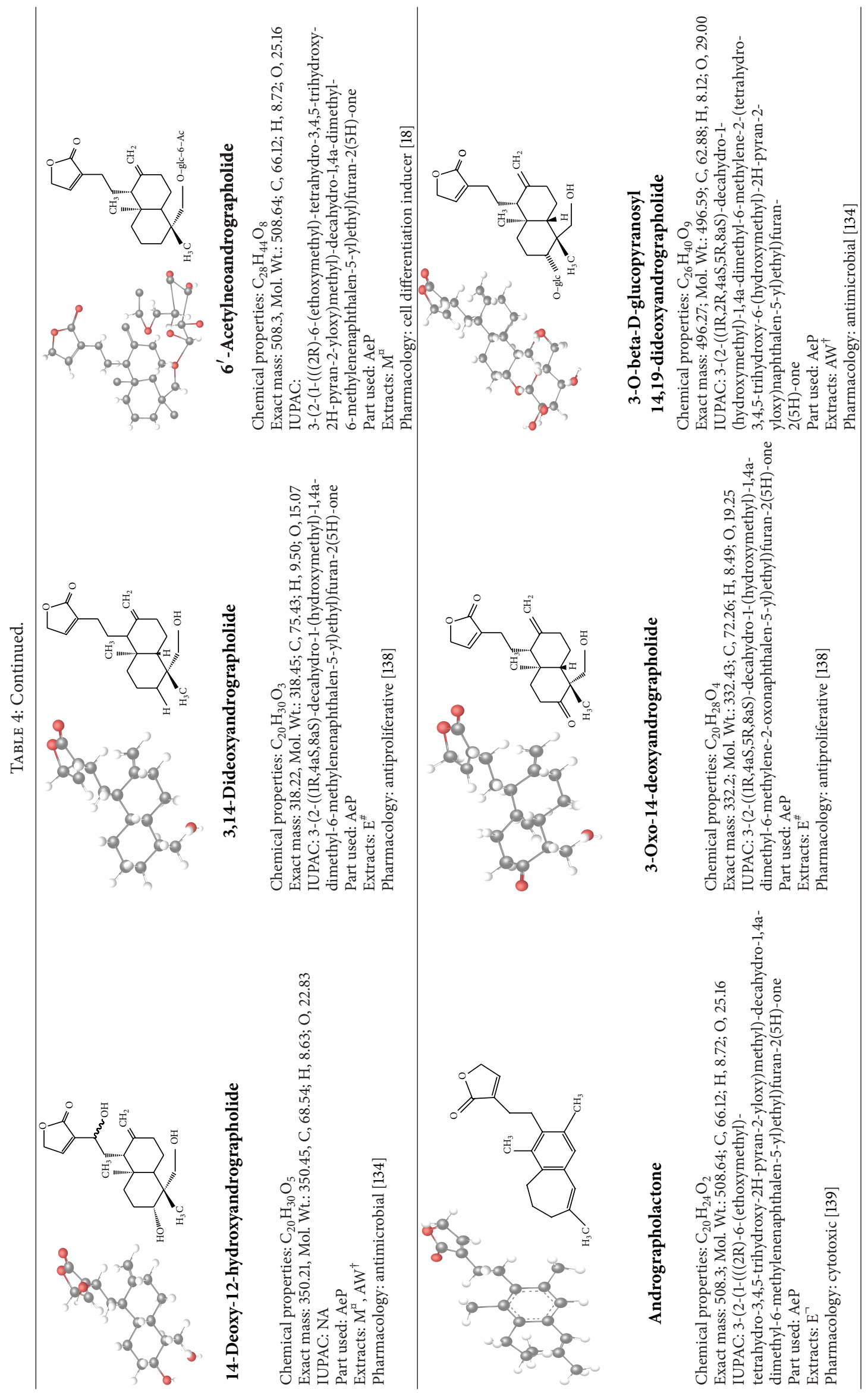




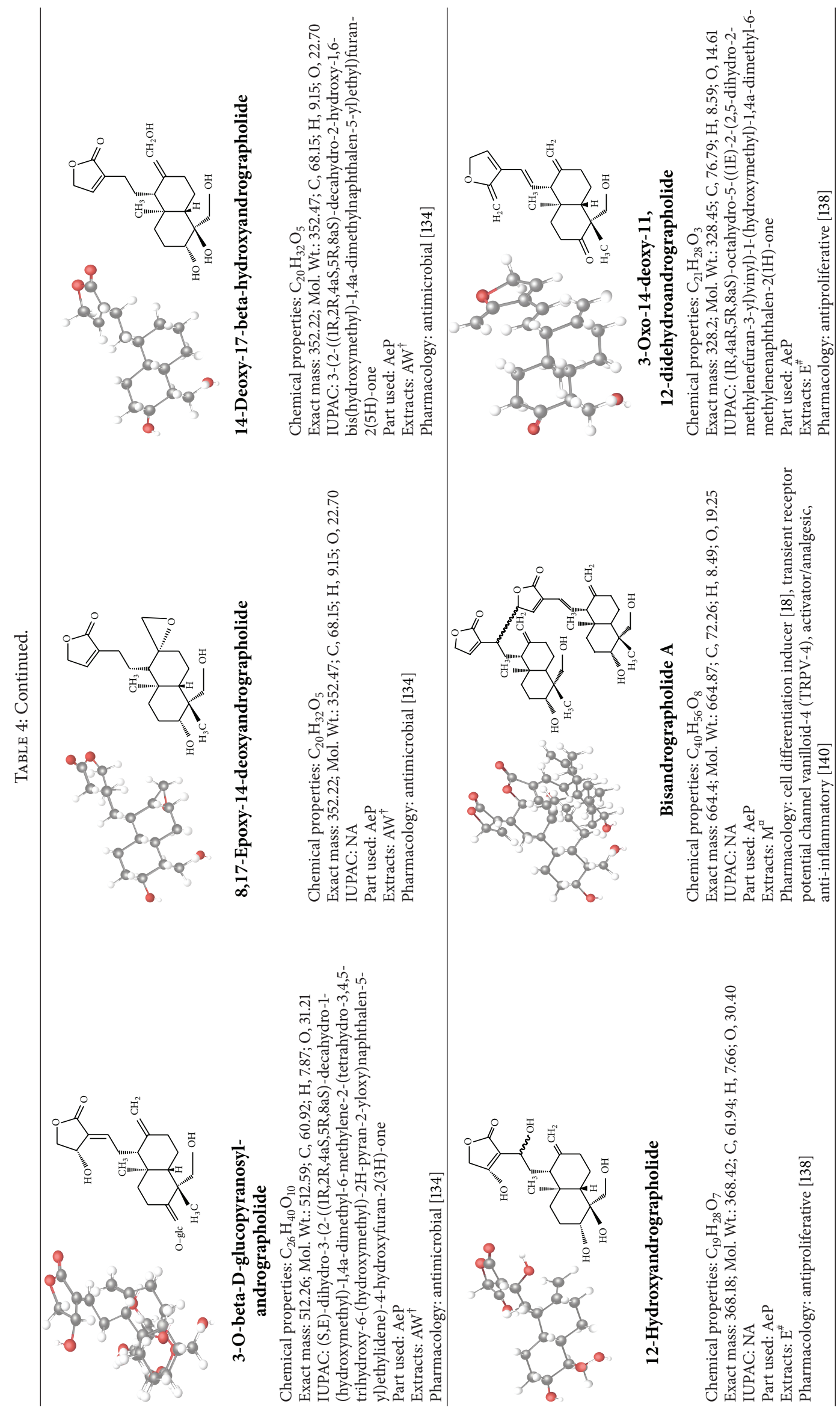




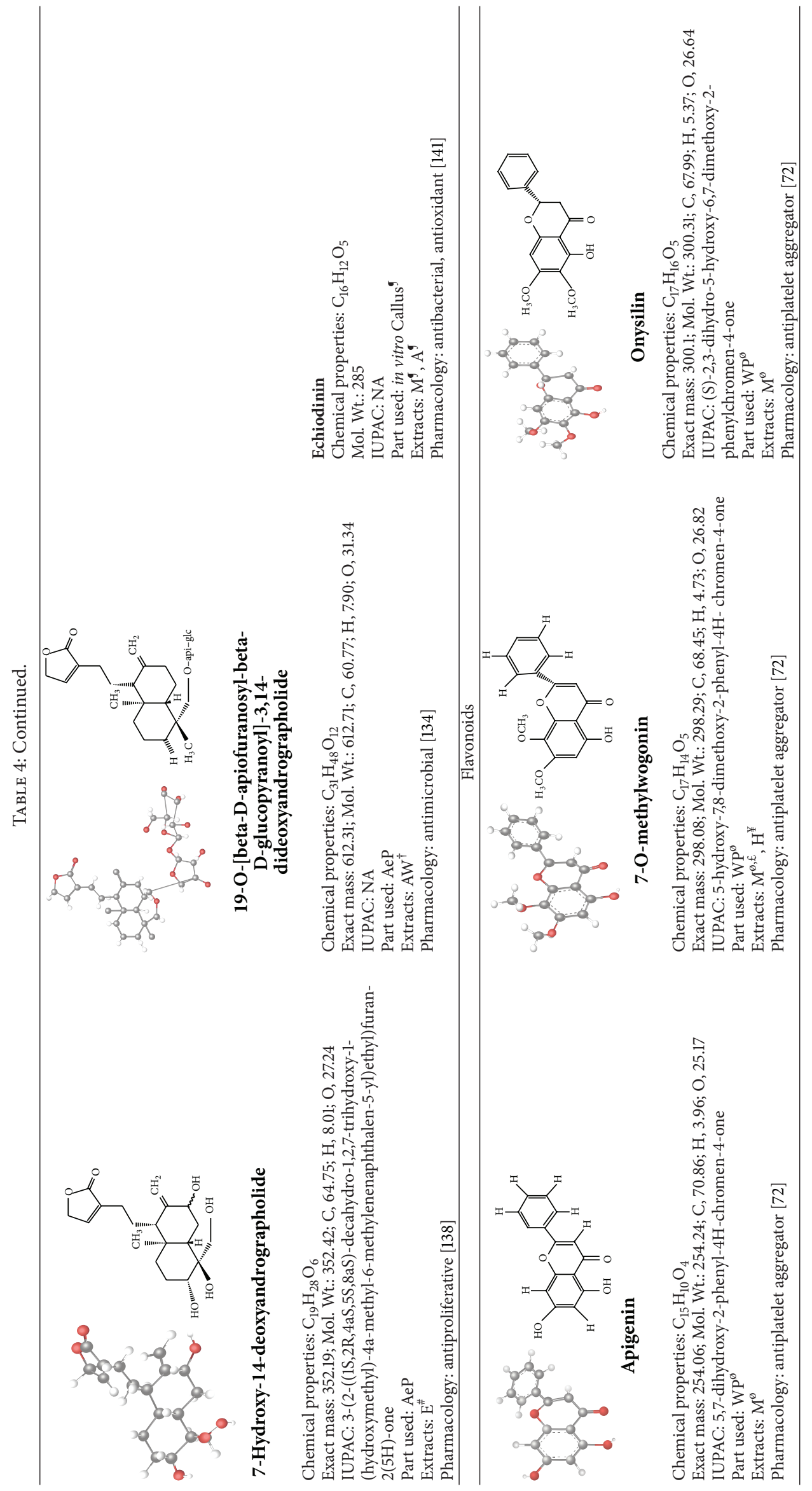




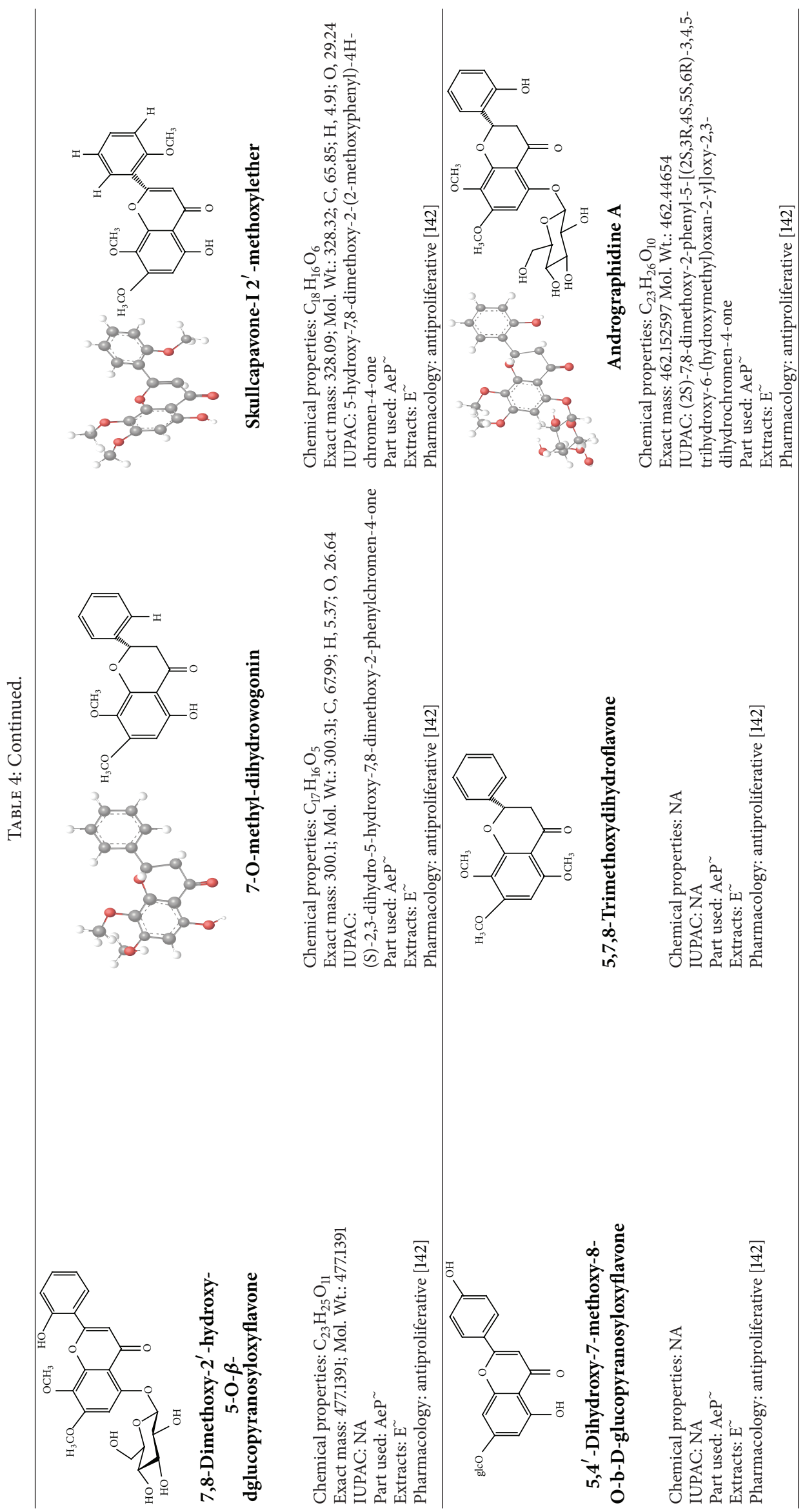




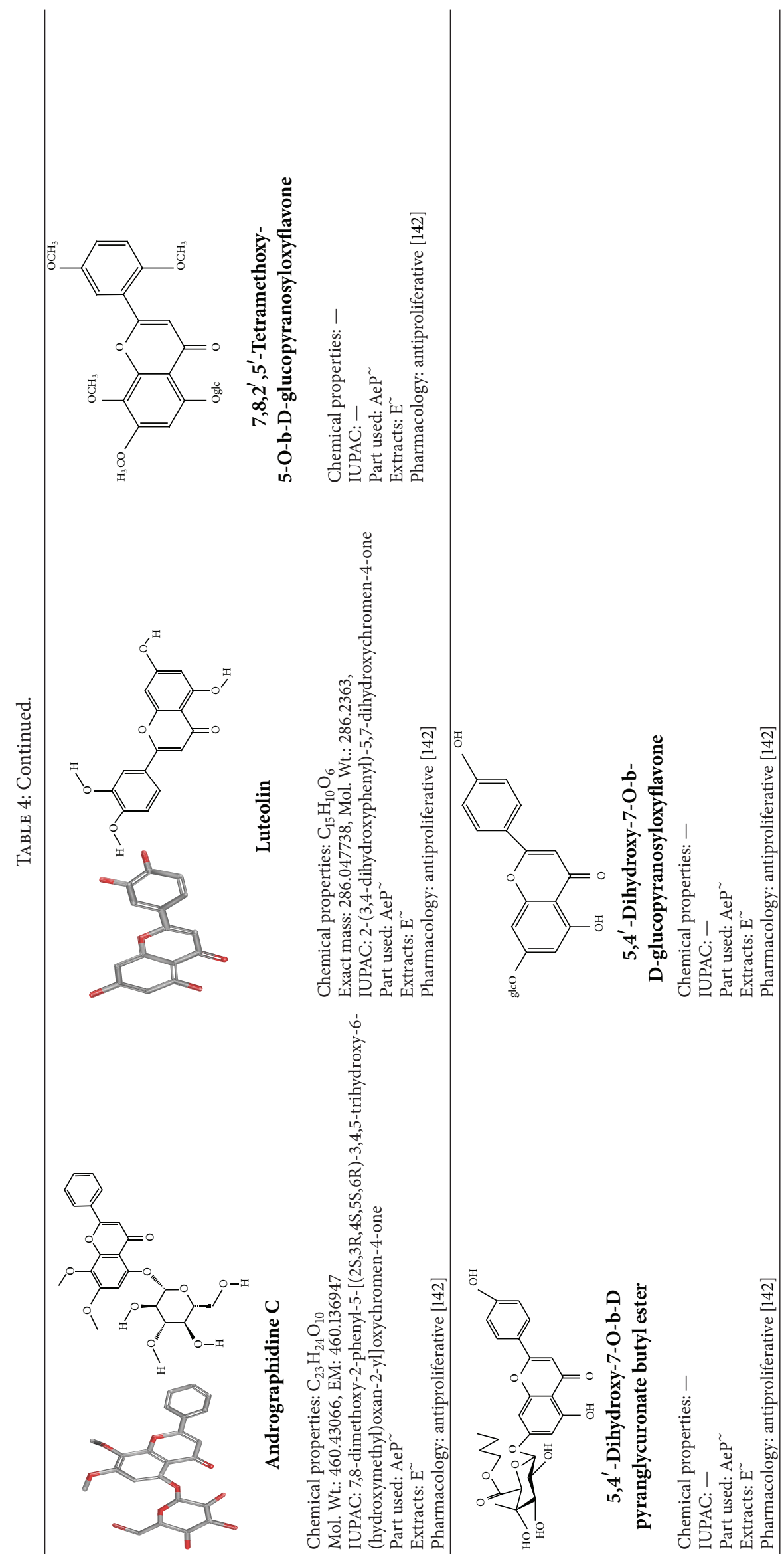




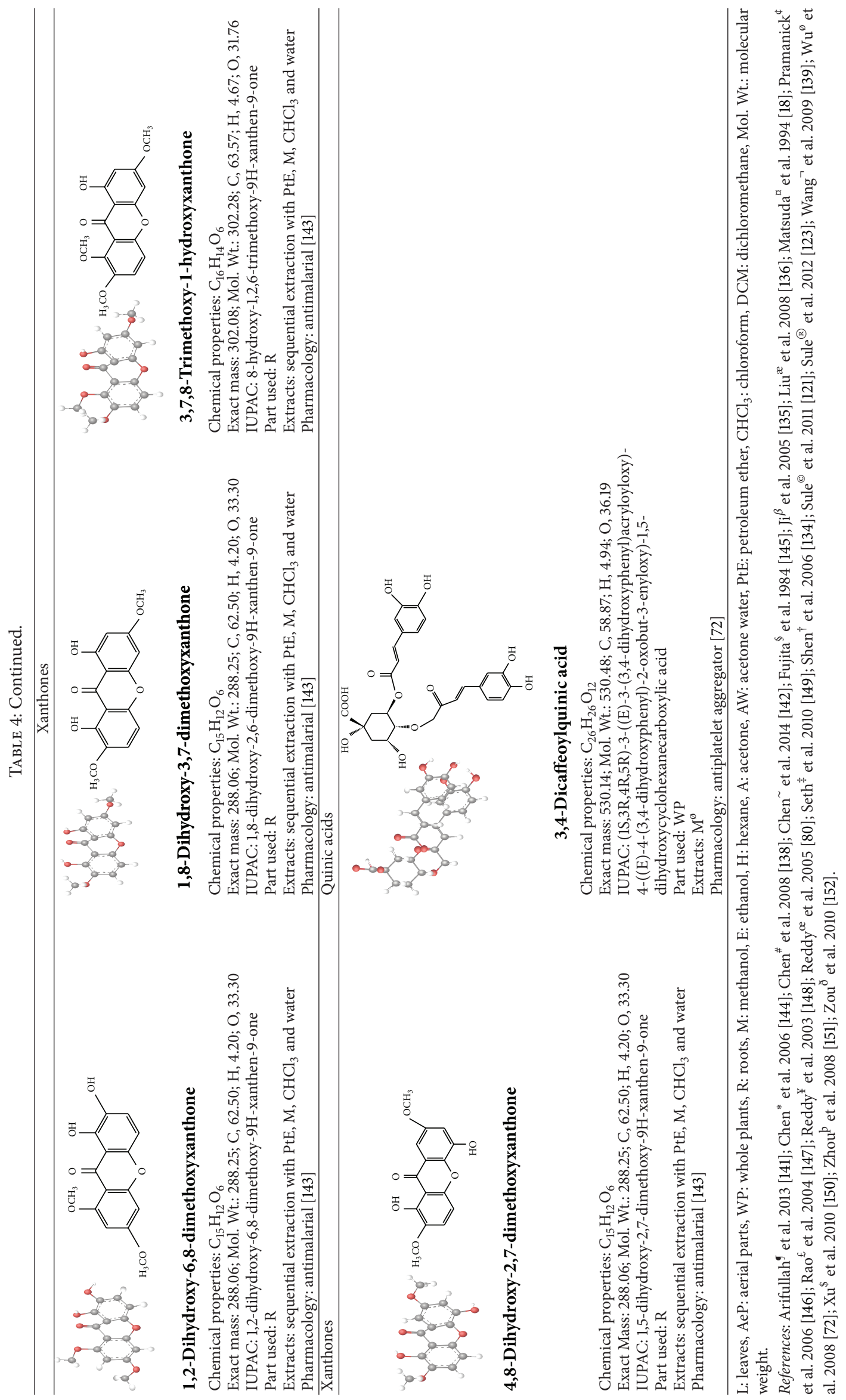


Besides the AP and andrographolide, andrographolide derivatives (e.g., CHP1002 and andrographolide sulfonate) also exhibited anti-inflammatory properties [182, 183]. CHP1002, a novel synthetic derivative of andrographolide, significantly inhibited LPS-induced iNOS, COX-2 expressions, iNOS derived nitric oxide (NO), and COX-2 derived prostaglandin $\mathrm{E}_{2}\left(\mathrm{PGE}_{2}\right)$ production through the stimulation of heme oxygenase-1 (HO-1) expression in RAW264.7 macrophages. CHP1002 also significantly faded LPSstimulated TNF- $\alpha$, IL-1 $\beta$, and IL-6 production [182]. Liu et al. [183] demonstrated that intraperitoneal administration of andrographolide sulfonate, a water soluble andrographolide (trade name: Xi-Yan-Ping injection), attenuated the severity of 2, 4, 6-trinitrobenzene sulfonic acid (TNBS) induced colitis in mice. A dose of $1.25-5 \mathrm{mg} / \mathrm{kg}$ of andrographolide sulfonate significantly recovered the loss of body weights and diarrhea in colitis mice, prevented inflammatory damages of colons and proinflammatory cytokines such as IFN- $\gamma$, IL-17A, and TNF- $\alpha$, and suppressed the functions of Thl and Th17 which is a feasible strategy to control inflammatory bowel disease. The demonstrated results suggested that andrographolide sulfonate could be a strong therapeutic compound for the treatment of gastrointestinal inflammatory disorders.

5.3. Antihyperglycemic Effect. Inhibitions of $\alpha$-glycosidase and $\alpha$-amylase activity and stimulation of insulin sensitivity are considered as effective strategies to lower the level of postprandial blood glucose. These enzymes involved in digestion and absorption of carbohydrates resulting in postprandial increase of blood glucose [184]. Insulin resistance is mainly expressed by hyperinsulinemia and high blood glucose level and is associated with some metabolic hormonal abnormalities, such as dyslipidemia, abnormal uric acid metabolism, increased ovarian testosterone secretion, endothelial dysfunction, elevated procoagulant factors, and elevated inflammatory markers [185]. AP extracts and andrographolide effectively showed antihyperglycemic effect by (a) lowering blood glucose level through inhibition of $\alpha$ glycosidase and $\alpha$-amylase [26, 27, 111, 186]; (b) increasing insulin sensitivity and thus stimulating glucose uptake and oxidation by peripheral tissues [94]; (c) controlling abnormal lipid metabolism; (d) scavenging free radicals from circulation which disrupt the plasma membrane integrity resulting in decreased number of efficient plasma membrane receptors or transporter proteins necessary to uptake glucose from the blood stream [187]. Blood glucose lowering effect of AP was observed in both insulin-lacking diabetic rats and normal rats in several studies [25, 186, 188, 189].

Andrographolide at a dose of $50 \mathrm{mg} / \mathrm{kg}$ effectively decreased blood glucose level, stimulated GLUT4 translocation [189], and improved diabetic rat's islet and beta cell functions [190]. Glucose induced hyperglycemia (orally administered) has been prevented by water extracts of AP in nondiabetic rats without affecting epinephrine-induced hyperglycemia [77]. Oral administration of ethanol extracts of AP significantly lowered the fasting blood glucose of human $[26,27,93,94]$. Another bioactive compound, namely 14-deoxy-11,12-didehydroandrographolide, also showed the antihyperglycemic activity [128].

Besides controlling blood glucose level, andrographolide also effectively prevented the onset of insulitis in a dose dependent manner and thus delayed the onset and suppressed the development of diabetes in 30-week-old NOD mice. Andrographolide also regulates the Th1/Th2/Th17 homeostasis through which it may prevent $\beta$-cell death and inhibit T-cell infiltration into pancreatic islets and thereby prevent development of type 1 diabetes [191]. Recently, Augustine et al. [187] reported that AP decreases the blood glucose by increasing glucose utilization and oxidation, restoration of insulin signaling molecules in liver, and decreasing the serum lipid levels in high fat and sucrose induced type 2 diabetic rats without showing hypoglycemic effect. A combination of n-hexane insoluble fraction of AP (HIFA) with curcuminoids fraction of Curcuma xanthorrhiza rhizome (CFC) also significantly showed the antihyperglycemic effect on high-fructosefat-fed rats [192]. The combination of HIFA-CFC could be a potential source to develop an antidiabetic agent. Therefore, the identification of more antihyperglycemic compounds of $\mathrm{AP}$ and combination of AP with other medicinal plants would be a focusing point of researchers for the better treatment option of the diabetic patients.

5.4. Hepatoprotective Effect. A. paniculata is widely used traditionally as a hepatoprotective agent and a stimulating agent for multiple enzymes of the liver. It is also used as an ingredient in the polyherbal preparations for the treatment of hepatic disorders in Ayurvedic and Unani medicine [8]. Along with different extracts of AP, andrographolide, neoandrographolide, 14-dexoyandrographolide, and 14-deoxy-11,12-didehydroandrographolide compounds are also reported to have hepatoprotective effect [40-42, 124, 129]. In a comparative study, the leaf extract and andrographolide was tested against the carbon tetrachloride$\left(\mathrm{CCl}_{4}-\right)$ induced hepatic microsomal lipid peroxidation. Only the leaf extract completely protected the high concentration $\mathrm{CCl}_{4}$-induced microsomal lipid peroxidation in vitro but not the andrographolide, which indicated that the hepatoprotective role is not solely due to the presence of andrographolide [48]. Similar effect of crude alcohol extracts of the AP leaves against $\mathrm{CCl}_{4}$-induced liver damage was also reported by Rana and Avadhoot [50]. Handa and Sharma [40] reported that andrographolide, methanol extract of whole plant, and andrographolide-free methanol extract improved liver histology in rats by $48.6 \%, 32 \%$, and $15 \%$, respectively, after $\mathrm{CCl}_{4}$-induced liver injury. Verma et al. [193] reported the effect of ethanol extract of AP on restoration of different enzyme after $\mathrm{CCl}_{4}$-induced liver injury. Further research using specific bioactive compounds is demanding for the better understanding of the hepatoprotective role played by the AP.

\subsection{Antimicrobial and Antiparasitic Effect}

5.5.1. Antibacterial Effect. Modern research has investigated the causes of extensive uses of AP in traditional healing 
systems as an antimicrobial agent to treat a variety of health morbidities of infectious origin. Leelarasamee et al. [194] reported that crude powder suspended in water to be devoid of in vitro antibacterial activity against Salmonella, Shigella, Escherichia coli, gram A Streptococci, and Staphylococcus aureus, even at a concentration of $25 \mathrm{mg} / \mathrm{mL}$ crude powder. However, over the last 3 decades, researchers reported that different types of extracts of $A$. paniculata possess potent antibacterial activity against various pathogenic and nonpathogenic bacteria. Nakanishi et al. [195] reported antibacterial activity of aqueous methanol $(50 \% \mathrm{v} / \mathrm{v})$ crude extracts of whole plant against Bacillus subtilis and Proteus vulgaris. Although Nakanishi et al. [195] reported the negative result against E. coli, ethanol extracts of aerial parts of AP were found to be effective in inhibiting $E$. coli growth along with other ten gram positive and gram negative bacteria species in an investigation conducted by Mishra et al. [196]. The aqueous extract showed significant antibacterial activity due to the combined effect of the isolated andrographolides and arabinogalactan proteins [197]. Similar effect was also mentioned by Fbricant and Farnsworth [198].

The antibacterial activity of three different extracts (dichloromethane, methanol, and aqueous) of AP whole plant was evaluated by Sule et al. [199] against 12 skin infection causing pathogenic bacterial strains. The extracts showed significant effects against all the tested bacterial strains in different concentrations likely 1000, 500, and $250 \mu \mathrm{g} / \mathrm{disc}$. However, methanol extract showed the highest antibacterial activity against Enterococcus faecalis at $1000 \mu \mathrm{g} / \mathrm{disc}$ with an inhibition zone of $24 \mathrm{~mm}$, and dichloromethane extract showed the least activity against Neisseria meningitis at $250 \mu \mathrm{g} / \mathrm{disc}$ with an inhibition zone of $6 \mathrm{~mm}$. Similar results again were reported in another manuscript by Sule et al. [200] in the following year. In their study, they investigated antibacterial activity of methanol extract of whole plant against five human pathogenic bacteria S. aureus, Streptococcus pyogenes, Micrococcus luteus, Proteus mirabilis, and P. aeruginosa. Their results revealed that the highest inhibition $(19.67 \pm 0.76 \mathrm{~mm})$ was exerted against $S$. aureus at $1000 \mu \mathrm{g} / \mathrm{mL}$ and the least $(07.00 \pm 1.50 \mathrm{~mm})$ activity shown against $P$. aeruginosae at $250 \mu \mathrm{g} / \mathrm{mL}$. However, it was a noteworthy result that the methanol extract exhibited more potent inhibitory activity against $S$. aureus $(19.67 \pm 0.76 \mathrm{~mm})$ and Streptococcus pyogenes $(16.00 \pm 0.58 \mathrm{~mm})$ at $1000 \mu \mathrm{g} / \mathrm{mL}$ compared to the antibiotic vancomycin $(17.00 \pm 1.05 \mathrm{~mm}$ and $14.50 \pm 1.00 \mathrm{~mm}$, resp.) [121]. Furthermore, they isolated and characterized two important antibacterial bioactive compounds, namely, 14-deoxyandrographolide (Figure 2) and 3-O- $\beta$-D-glucosyl14-deoxyandrographolide, from the whole plant of AP and concluded that the mentioned efficacy of methanol extract had been shown due to the presence of these compounds (Table 4).

5.5.2. Antiviral Effect. Researchers investigated significant antiviral activity of AP besides other pharmacological activities in last two decades. Although they reported antiviral activity against limited viruses, such as dengue virus serotype 1 (DENV-1) [201], human papilloma virus type 16 (HPV16) [202], herpes simplex virus type 1 (HSV-1) [203], influenza
A virus [102], and $\operatorname{HIV}[53,55,80,204]$, their findings were very encouraging and noteworthy considering the life threatening role of these viruses in human community. The hot aqueous aerial parts extract of AP was reported for its significant antiviral activity to reduce the percentage of HIV antigen-positive H9 cells [55]. Recently, Tang et al. [201] reported that the methanol extract of AP possesses significant inhibition activity against DENV-1 in vitro assay. Another study has revealed that andrographolide suppressed HPV16 transcription activity, leading to the reduction of E6 oncoprotein and restored p53 [202].

Several bioactive compounds such as andrographolide, neoandrographolide, dehydroandrographolide, natural derivatives of andrographolide, namely, 14-deoxy-11,12-didehydroandrographolide and 14-deoxyandrographolide, and synthetic derivatives, namely, dehydroandrographolide succinic acid monoester (DAMS), 14- $\alpha$-lipoyl andrographolide (AL-1), 14-acetyl-3,9-isopropyl-ideneandrographolide, 14-acetylandrographolide, 3,14,19-triacetylandrographolide, and 3,9isopropyl-ideneandrographolide have been shown to have significant antiviral activity against HIV, influenza A, and HSV-1 without any significant cytotoxic effect at virucidal concentrations. Andrographolide, isolated from ethanol extracts of whole plant of AP, showed a great promise in the treatment of HIV infections. It might be able to inhibit viral replication by interfering $\mathrm{CDK}$ (cyclin dependent kinase) activity, resulting in deregulation of HIV induced cell cycle $[53,80,205]$. The overall findings of andrographolide effects against different viruses indicate that andrographolide would be an effective agent for prevention and treatment of viral diseases.

5.5.3. Antiparasitic Effect. Antiparasitic activity of the AP extract is reported in certain articles. Dua et al. [143] investigated both in vitro and in vivo antimalarial activity of four xanthones (Table 4) isolated from roots against Plasmodium falciparum and Plasmodium berghei. One of the xanthones, 1,2-dihydroxy-6,8-dimethoxy-xanthone, showed substantial antiplasmodial activity during in vitro $\left(4 \mu \mathrm{g} / \mathrm{mL}\right.$ at $\mathrm{IC}_{50}$ value $)$ and in vivo (62\% parasitaemia reduction at $30 \mathrm{mg} / \mathrm{Kg}$ dose) study.

The water extract of dried leaves was found to be active against adult worms of Brugia malayi in vitro [206]. Recently, Padma et al. [207] evaluated the aqueous and methanol extracts for in vitro anthelmintic activity against adult earth worms Pheretima posthuma. The extracts showed significant results at the concentrations of $25 \mathrm{mg} / \mathrm{mL}, 50 \mathrm{mg} / \mathrm{mL}$, and $75 \mathrm{mg} / \mathrm{mL}$. However, the clinical relevancies of the antiparasitic studies are inconclusive due to obtaining the results at high concentration that may not be feasible clinically.

5.6. Anticancer Effect. Andrographolide exhibited both direct and indirect effects on cancer cells by inhibiting proliferation of cancer cells, cell-cycle arrests, or cell differentiation, enhancing body's own immune system against cancer cells; and inducting apoptosis and necrosis of cancer cells [208]. Dichloromethane fraction of methanol extract significantly inhibited the proliferation of HT-29 colon cancer cells. The major bioactive compound of AP, andrographolide, isolated 
from dichloromethane inhibited the growth of a diverse cancer cell representing different types of human cancers [11]. In contrast, recently Aditya et al. [209] reported that methanol extract of AP was found to be very less effective against both MCF-7 breast and HT-29 colon cancer cell lines. This low activity exhibited might be due to the low penetration power of the active principles.

Antiproliferative activities of andrographolide and isoandrographolide along with other 16 ent-labdane diterpenoids isolated from $85 \%$ ethanol extract of AP against human leukaemia HL-60 cells have also been investigated by Chen et al. [138]. These results showed that andrographolide and isoandrographolide were more effective than others. In a recent study, Chen et al. [142] identified a new flavonoid, 7, 8dimethoxy-2' -hydroxy-5-O- $\beta$-d-glucopyranosyloxyflavone, isolated from the aerial parts of AP. This flavonoid exhibited potent antiproliferative activity against human leukaemia HL-60 cells with $\mathrm{IC}_{50}$ of $3.50 \mu \mathrm{M}$. Ethanol (70\%) extracts and andrographolide were also found to be effective to increase the life spans of thymoma injected mice cells in an in vivo study [83]. In the following year, Geethangili et al. [210] showed the effective cytotoxic activity of ethanol extracts against human cancer cells including Jurkat (lymphocytic), PC-3 (prostate), HepG2 (hepatoma), and colon 205 (colonic) cancer cells. In another study, use of andrographolide at a dose $12 \mu \mathrm{g} / \mathrm{mL}$ for $36 \mathrm{~h}$ against HL-60 cells improved $27 \%$ in G0/G1 phase cells and significantly decreased cells number at $S$ and G2/M phase [12]. Shi et al. [82] reported that andrographolide can inhibit human colorectal carcinoma (CRC) Lovo cell growth by G1-S phase arrest and induce the expression of cell-cycle inhibitory proteins p53, p21, and p16. These proteins repressed the activity of cyclin D1/Cdk4 and/or cyclin A/Cdk2, required for G1 to S phase transition. In a recent in vitro study, andrographolide has been shown to suppress the growth and invasion of CRC Lovo cells and trigger apoptosis. Besides the effect of andrographolide alone, andrographolide in combination with chemotherapeutics, cisplatin, is likely to represent a potential therapeutic strategy for CRC [211].

Andrographolide and its analogues exert direct inhibitory effect on cancer cells by inducing expression of cell cycle inhibitory proteins and depressing cyclin-dependent kinase (Cdk) resulting in blocking the cell cycle progression at G0/G1 [12, 13, 82, 212, 213]. Some other compounds also block the cell cycle progression at G2/M phase [210]. A novel semisynthetic analogue of andrographolide, DRF3188, exhibited anticancer activities against MCF 7 breast cancer cells at a lower dosage than andrographolide through similar mechanism [212]. Both the compounds block cell cycle at the G0-G1 phase through induction of the cell cycle inhibitor (p27) and concomitant decrease in the levels of Cdk4. Therefore, attention has been focused on the anticancer properties of pure components of AP and the molecular target of andrographolide that blocks G1 stage still needs to be determined.

5.7. Immunomodulatory Effect. Control of immune response by regulating nuclear factor of activated $\mathrm{T}$ cells (NFAT), a transcription factor essential for cytokine production during
T-cell activation, is a widely known strategy. Preventing translocation of NFAT to nucleus is the target of several immunosuppressive agents (e.g., cyclosporin A, FK506) [112]. AP is known to exert several immunomodulatory properties. More than two decades ago, a laboratory test demonstrated that AP inhibited growth of human breast cancer cells similar to the drug tamoxifen [17]. Amroyan et al. [214] reported that andrographolide was effective to stop the clumping of blood platelets that lead to heart attacks and they also suggested that andrographolide has a major effect on activating the general defense functions of immune system by stimulating the production of antibodies as well as nonspecific immune responses such as increased macrophage phagocytosis. An in vitro study with the increased proliferation of lymphocytes and production of interleukin-2 (IL-2) confirmed the immunostimulatory activity of AP [12]. Three diterpene compounds of AP isolated from dichloromethane fraction of methanol extract showed augmented proliferation and IL-2 induction in human peripheral blood lymphocytes (HPBLs) at a low concentration [11]. In addition, the chronic consumption of the aqueous extract of AP also promoted the immune functions at $250 \mathrm{mg} / \mathrm{kg}$ and $500 \mathrm{mg} / \mathrm{kg}$; however, $1000 \mathrm{mg} / \mathrm{kg}$ dose leading to development of autoimmune reactions, anaemia and multiple myeloma [215]. AP extract and andrographolide significantly promoted the lyses of natural killer (NK) cell-mediated target cells on day 5 after tumor induction. Antibody dependent cell mediated cytotoxicity (ADCC) and antibody dependent complement-mediated cytotoxicity (ACC) in metastatic tumor bearing animals were also enhanced significantly compared to the control by the treatment of AP extract and andrographolide. In addition, the levels of proinflammatory cytokines such as IL-1 $\beta$, IL-6, GMCSF, and TNF- $\alpha$ were also effectively reduced [216]. Carretta et al. [112] demonstrated that andrographolide reduces IL-2 production, extracellular signal regulated kinase- (ERK-) 1 and ERK-5 phosphorylation induced by anti-CD3 or phorbol myristate acetate and ionomycin (PMA/Ionomycin), and NF$\kappa \mathrm{B}$ activity in Jurkat cells and this effect can be related to a reduction in NFAT activity and an increase in c-jun-Nterminal kinase (JNK) phosphorylation. Moreover, andrographolide inhibited tumor growth in animals by stimulating the production of cytotoxic T lymphocytes [83]. Hence, the compounds modulate the host immune systems against these cells to confer the direct cytotoxicity to cancer cells. Based on the reported immunomodulatory properties, AP and andrographolide might be effective clinically to treat the autoimmune diseases.

5.8. Cardiovascular Effect. Cardiovascular diseases (CVDs) are the leading cause of death throughout the world. AP is used widely for improving the cardiac health in traditional medicinal systems. Several studies have investigated its activities in cardiovascular diseases [38, 81, 107, 131, 217225]. Wang et al. [222] reported that AP is potential to increase the nitric oxide, cyclic guanosine monophosphate, and superoxide dismutase activity with declines of lipid peroxide and endothelin in an atherosclerotic rabbit model. In another study, Wang and Zhao [223] also investigated that the AP extracts can be able to prevent constriction of blood 
vessels and increase blood clotting time significantly in the pre- and postangioplasty procedures. The extracts inhibited the cell growth and DNA synthesis in a dose dependent manner, which is a similar mechanism like stents that prevent cell division.

Aqueous extracts and active constituents of AP showed significant antihypertensive activity in both spontaneously hypertensive rats and normotensive Wister-Kyoto rats [226], improved the blood pressure status in both pre- and post experimental myocardial infarction in animals $[217,218]$, and exhibited platelet antiaggregation in in vitro [81, 214] and ex vivo [227] assays. The existing reports suggested that AP can be used as alternative source of the treatment of CVDs. Further studies are necessary to know the insight of the mechanism of actions of specific constituents of AP and in clinical perspectives.

5.9. Antihyperlipidemic Effect. Hyperlipidemia is an important factor for atherosclerosis that leads to heart attack (obstruction occurs in the coronary arteries) and stroke (obstruction occurs in the arteries of the brain) [228-230]. Chen et al. [231] suggested the andrographolide as candidate therapeutic agent for atherosclerosis based on their research result. Recently, another study revealed antihyperlipidemic effects of andrographolide and neoandrographolide [225]. Yang et al. [225] reported the effects of andrographolide and neoandrographolide on hyperlipidemic mice induced by $75 \%$ yolk emulsion and hyperlipidemic rats induced by high fat emulsion. Andrographolide and neoandrographolide reduced triglyceride, total cholesterol, and lowdensity lipoprotein cholesterol in a dose dependent manner. Plasma aspartate transaminase and alanine transaminase levels were also significantly $(P<0.01)$ reduced compared to the positive control (Simvastatin). These compounds exhibited their lipid and lipoprotein reducing effects through downregulation of iNOS expression and upregulation of eNOS expression in aorta of hyperlipidemic rats [225]. The results of hypolipidemic study require further exploration of the molecular mechanism and the related signaling pathway.

5.10. Sexual Functions and Contraceptive Effect. AP and andrographolide showed earlier either contraceptive [58, 232-236], fertility [237-239], or no effects [240] in a variety of studies. AP showed contraceptive effects by terminating spermatogenesis in male albino rats $[233,236]$. Zoha et al. [232] reported that there were no pregnant female mice that consumed AP mixed food daily after mating with the untreated male of potential fertility, which means that the AP has contraceptive effect on female mice. AP and andrographolide were effective to prevent cytokinesis of dividing spermatogenic cell lines resulting in stopped spermatogenesis $[235,236]$. The antifertility effects of andrographolide are characterized by marked decreases of protein content along with significant increases of cholesterol, acid phosphatase, and alkaline phosphatase levels with appearance of fructose in the reproductive systems of rats [234]. Panossian et al. [241] reported negative results of AP's powdered extract on blood progesterone content in rats. However, the testosterone level with mounting frequency was significantly increased in mice at 4 weeks of andrographolide treatment. There was no toxicity of andrographolide $(50 \mathrm{mg} / \mathrm{kg})$ treatment for up to 8 weeks on number and motility of sperm. Further studies are needed to confirm the double stand activities of AP and andrographolide on female and male sexual behaviors. The investigation of specific mechanisms in regulation of fertility and contraceptive effects of AP and its active constituents would be valued to identify target point of controlling sexual behaviors.

5.11. Safety and Toxicity Effects. Generally, uses of AP as a medicine have been proved to be safe in various studies on mice, rats, and rabbits, as well as in in vitro assays and some clinical trials. Some conflicting results are also available. Few studies showed the toxic effect of AP on reproductive system by damaging the Sertoli cell in male gonads in albino rats. A dose of 25 and $50 \mathrm{mg} / \mathrm{kg}$ body weight for a period of 48 days demonstrated that antispermatogenic effect $[58,235$, 236]. However, contradictory result was also demonstrated by numerous studies [237, 239, 240, 242-245]. The safety of AP extracts regarding the oral acute toxicity $(>17 \mathrm{~g} / \mathrm{Kg}$, $\left.\mathrm{LD}_{50}\right)$ [237], testicular toxicity $\left(>1 \mathrm{~g} / \mathrm{Kg}, \mathrm{LD}_{50}\right)$ [240], and genotoxicity $\left(5 \mathrm{~g} / \mathrm{Kg}, \mathrm{LD}_{50}\right)$ [244] has been reported.

Due to AP's extreme bitterness, it may cause emesis. Some adverse effects including allergic reaction, gastric instability, fatigue, headache, loss of appetite, lymphadenopathy, diarrhea, metallic taste, and nausea are also observed in overdosing of AP extracts $[63,246]$. It is suggested to avoid this plant during pregnancy due to ovulation preventive effects of the plant [232]. To date, all trials with few exceptions were for short duration; thus the prediction of safety for long term use would be farfetched.

\section{Future Direction}

Pharmacological activity of AP was investigated either using crude extracts or isolated bioactive compounds. Though the crude extract showed significant effects, isolation of bioactive compounds and investigation of pharmacology provide more specific knowledge especially about mechanism of actions of compounds. Conventional extraction processes (such as soxhlet extraction, maceration, and hydrodistillation) have been using by most of the researchers all over the world. However, selection of proper extraction methods is crucial for qualitative and quantitative studies of bioactive compounds derived from medicinal plant [247].

The reported pharmacology of bioactive compounds of AP is based on conventional extraction methods with few exceptions using different solvents, for example, methanol, ethanol, water, acetone, acetone-water, chloroform, and dichloromethane (Table 4). The conventional extraction techniques have some limitations including longer extraction time, costly and high purity solvent required, huge amount of solvent evaporation, low extraction selectivity, and thermal decomposition of thermolabile compounds. To overcome these problems, some new and promising extraction methods like ultrasound assisted extraction, enzyme-assisted extraction, microwave-assisted extraction, pulsed electric field assisted extraction, supercritical fluid extraction, and 
pressurized liquid extraction have been introduced which are termed as nonconventional extraction methods [248]. Some of these techniques are known as "green techniques" and are applicable for high yield and more purified compounds within a short time compared to classical methods. For example, extraction of phenolic antioxidants from five citrus peels (Yen Ben lemon, Meyer lemon, grapefruit, mandarin, and orange) by enzyme-assisted extraction was improved significantly with higher enzyme concentration [249]. Howard and Pandjaitan [250] extracted flavonoids from spinach by pressurized liquid extraction effectively. Therefore, it can be suggested that extraction of bioactive compounds from AP using nonconventional extraction methods of bioactive compounds would be valued to get high yield and purified compounds.

We mentioned earlier that tissue culture techniques have been applied successfully to form new flavones by differentiating callus culture. Jalal et al. [168] reported that differentiating tissue cultures of AP produce three new flavones, 5hydroxy-7,8,2' -trimethoxy-, 5,2' -dihydroxy-7,8-dimethoxy-, and 5-hydroxy-7,8-dimethoxy-flavones. Arifullah et al. [141] isolated andrographolide and echiodinin from in vitro leaf callus of AP. In vitro root culture system can be exploited as a renewable source of minerals essential for designing effective drugs [167]. Other bioactive compounds can also be extracted via tissue culture. Adventitious roots from vegetative propagation of AP can also be an alternative source of plant materials for extraction of bioactive compounds from roots. We investigated a rapid and maximum adventitious roots in AP's shoot microcuttings applying soaking method at 3 mM IBA (Indole-3-butyric acid) (Figure 1(f)) (unpublished data). These adventitious roots can be further investigated to see the quality and content of bioactive compounds and pharmacological effects. Hence, adventitious rooting and plant tissue culture techniques can be alternative ways to meet the commercial demand of AP.

Stress alters growth and development of plants. In our investigation, we found that salinity stress showed deleterious effects on morphophysiological parameters including colour, plant height, leaf area, and root length of AP. It also causes less production of AP [251]. The stress conditions have a strong impact on the responsible metabolic pathways for the accumulation of the related natural products [252]. However, abiotic stress condition (as an agronomical approach) [253, 254] and biotechnological approaches (genetic transformation) [255] can be used to improve the content of some active compounds like flavonoids on a large scale in plants. Talei et al. [256] reported that high salinity level $(16 \mathrm{dS} / \mathrm{m})$ reached relatively higher andrographolide and neoandrographolide content compared to control. The increase in andrographolide and neoandrographolide contents at high salinity level $(16 \mathrm{dS} / \mathrm{m})$ was $177.57 \%$ and $131.18 \%$ compared to the control, respectively. Optimization of the yield of andrographolide and neoandrographolide content and investigation of other important bioactives of AP under abiotic stresses would be valued to meet the commercial demand of bioactive compounds of AP. To date, to our knowledge, any investigation of pharmacological activities of bioactive compounds obtained from salinity treated AP is not conducted yet. Therefore, it is very crucial to know the comparative efficacy of the compounds obtained from salinity treated and control AP. The obtained knowledge from the suggested study could also be used for further research design on AP for the betterment of human health.

\section{Conclusion}

The demand of AP is greatly increased in the past few years for its overwhelming therapeutic potentials. Available data on AP also clearly expresses a broad spectrum of pharmacological properties of this plant. Due to possessing extensive pharmacological activities, the AP can be safely regarded as one of the modern catholicons. However, the investigated pharmacological activities of AP need validation through the clinical study. Though several clinical studies were successfully completed without adverse effects or fatalities, most of them only investigated upper respiratory tract infections for a variety of conditions. Verification of the efficacy of other biological activities of AP including antidiabetic, anticancer, anti-inflammatory, and hepatoprotective activities, on human study subjects would bring a lot of benefits for the largest population of the globe. We assume that the AP could be useful as highly applied therapeutic agents for a variety of disorders in the near future to cure human diseases as well as some animal diseases. To fulfill this dream, the researchers might focus on multiplication of this plant to meet commercial demand besides the pharmacology study. Tissue culture techniques might be a good alternative to make AP available for researches (i.e., pharmacological study and phytochemical study to find new bioactive compounds) as well as conservation of this plant.

\section{Disclosure}

This study was not involved in any handling of animals or live species.

\section{Conflict of Interests}

The authors have no conflict of interests to declare.

\section{Acknowledgments}

The authors would like to express their cordial thanks to Prof. Dr. Ahmed Jalal Khan Chowdhury from International Islamic University Malaysia, for his admirable inspiration. The authors' appreciation is also extended to Br. Abdur Razzak and Br. Md. Al Amin for their assistance in providing useful papers for the review. The authors are also grateful to Mr. Mohammad Ibrahim Auli Ullah from Universiti Sultan Zainal Abidin, Kuala Terengganu, Malaysia, for his critical proof reading of this paper.

\section{References}

[1] G. Chaudhary, S. Goyal, and P. Poonia, "Lawsonia inermis Linnaeus: a phytopharmacological review," International Journal of Pharmaceutical Sciences and Drug Research, vol. 2, no. 2, pp. 9198, 2010. 
[2] P. Joy, J. Thomas, S. Mathew, and B. P. Skaria, "Medicinal plants," Tropical Horticulture, vol. 2, pp. 449-632, 1998.

[3] I. H. Burkill, W. Birtwistle, F. Foxworthy, J. Scrivenor, and J. Watson, A Dictionary of the Economic Products of the Malay Peninsula, Ministry of Agriculture and Co-operatives, Kuala Lumpur, Malaysia, 1966.

[4] G. Kavishankar, N. Lakshmidevi, S. M. Murthy, H. Prakash, and S. Niranjana, "Diabetes and medicinal plants-a review," Journal of Pharmaceutical and Biomedical Sciences, vol. 2, no. 3, pp. 65-80, 2011.

[5] R. Hajiaghaee and S. Akhondzadeh, "Herbal medicine in the treatment of Alzheimer's disease," Journal of Medicinal Plants, vol. 11, no. 41, pp. 1-7, 2012.

[6] Z. Urbi, S. Hossain, K. M. Hafizur Rahman, and T. M. Zayed, "Grape: a medicinal fruit species in the holy Qur'an and its ethnomedinical importance," World Applied Sciences Journal, vol. 30, no. 3, pp. 253-265, 2014.

[7] J. A. Duke, Duke's Handbook of Medicinal Plants of the Bible, CRC Press, Taylor \& Francis, 2007.

[8] S. Akbar, "Andrographis paniculata: a review of pharmacological activities and clinical effects," Alternative Medicine Review, vol. 16, no. 1, pp. 66-77, 2011.

[9] M. H. Kabir, N. Hasan, M. M. Rahman et al., "A survey of medicinal plants used by the Deb barma clan of the Tripura tribe of Moulvibazar district, Bangladesh," Journal of Ethnobiology and Ethnomedicine, vol. 10, no. 1, article 19, 2014.

[10] K. Jarukamjorn and N. Nemoto, "Pharmacological aspects of Andrographis paniculata on health and its major diterpenoid constituent andrographolide," Journal of Health Science, vol. 54, no. 4, pp. 370-381, 2008.

[11] R. Ajaya Kumar, K. Sridevi, N. Vijaya Kumar, S. Nanduri, and S. Rajagopal, "Anticancer and immunostimulatory compounds from Andrographis paniculata," Journal of Ethnopharmacology, vol. 92, no. 2-3, pp. 291-295, 2004.

[12] S. Rajagopal, R. A. Kumar, D. S. Deevi, C. Satyanarayana, and R. Rajagopalan, "Andrographolide, a potential cancer therapeutic agent isolated from Andrographis paniculata," Journal of Experimental Therapeutics and Oncology, vol. 3, no. 3, pp. 147-158, 2003.

[13] H.-Y. Cheung, S.-H. Cheung, J. Li et al., "Andrographolide isolated from Andrographis paniculata induces cell cycle arrest and mitochondrial-mediated apoptosis in human leukemic HL60 cells," Planta Medica, vol. 71, no. 12, pp. 1106-1111, 2005.

[14] W. Li, X. Xu, H. Zhang et al., "Secondary metabolites from Andrographis paniculata," Chemical and Pharmaceutical Bulletin, vol. 55, no. 3, pp. 455-458, 2007.

[15] S. Harjotaruno, A. Widyawaruyantil, and N. C. Zaini, "Apoptosis inducing effect of andrographolide on TD-47 human breast cancer cell line," African Journal of Traditional, Complementary and Alternative Medicines, vol. 4, no. 3, pp. 345-351, 2008.

[16] J. Zhou, S. Zhang, O. Choon-Nam, and H.-M. Shen, "Critical role of pro-apoptotic Bcl-2 family members in andrographolide-induced apoptosis in human cancer cells," Biochemical Pharmacology, vol. 72, no. 2, pp. 132-144, 2006.

[17] A. Puri, R. Saxena, R. P. Saxena, K. C. Saxena, V. Srivastava, and J. S. Tandon, "Immunostimulant agents from Andrographis paniculata," Journal of Natural Products, vol. 56, no. 7, pp. 995999, 1993.

[18] T. Matsuda, M. Kuroyanagi, S. Sugiyama, K. Umehara, A. Ueno, and K. Nishi, "Cell differentiation-inducing diterpenes from Andrographis paniculata Nees," Chemical and Pharmaceutical Bulletin, vol. 42, no. 6, pp. 1216-1225, 1994.
[19] S. Gupta, M. A. Choudhry, J. N. S. Yadava, V. Srivastava, and J. S. Tandon, "Antidiarrhoeal activity of diterpenes of Andrographis paniculata (Kal-Megh) against Escherichia coli enterotoxin in in vivo models," International Journal of Crude Drug Research, vol. 28, no. 4, pp. 273-283, 1990.

[20] S. Gupta, J. N. S. Yadava, and J. S. Tandon, "Antisecretory (antidiarrhoeal) activity of Indian medicinal plants against Escherichia coli enterotoxin-induced secretion in rabbit and guinea pig ileal loop models," International Journal of Pharmacognosy, vol. 31, no. 3, pp. 198-204, 1993.

[21] A. Sharma, R. T. Singh, V. Sehgal, and S. S. Handa, "Antihepatotoxic activity of some plants used in herbal formulations," Fitoterapia, vol. 62, no. 2, pp. 131-138, 1991.

[22] W. Tang and G. Eisenbrand, "Andrographis paniculata (Burm. f.) Nees," in Chinese Drugs of Plant Origin Chemistry, Pharmacology, and Use in Raditional and Modern Medicine, W. Tang and G. Eisenbrand, Eds., pp. 97-103, Springer, Berlin, Germany, 1992.

[23] S. Nanduri, V. K. Nyavanandi, S. Sanjeeva Rao Thunuguntla et al., "Synthesis and structure-activity relationships of andrographolide analogues as novel cytotoxic agents," Bioorganic and Medicinal Chemistry Letters, vol. 14, no. 18, pp. 4711-4717, 2004.

[24] B.-C. Yu, C.-R. Hung, W.-C. Chen, and J.-T. Cheng, "Antihyperglycemic effect of andrographolide in streptozotocin-induced diabetic rats," Planta Medica, vol. 69, no. 12, pp. 1075-1079, 2003.

[25] B. C. Yu, C. K. Chang, C. F. Su, and J. T. Cheng, "Mediation of $\beta$-endorphin in andrographolide-induced plasma glucoselowering action in type I diabetes-like animals," NaunynSchmiedeberg's Archives of Pharmacology, vol. 377, no. 4-6, pp. 529-540, 2008.

[26] R. Subramanian and M. Z. Asmawi, "Inhibition of $\alpha$-glucosidase by Andrographis paniculata ethanol extract in rats," Pharmaceutical Biology, vol. 44, no. 8, pp. 600-606, 2006.

[27] R. Subramanian, M. Z. Asmawi, and A. Sadikun, "In vitro $\alpha$-glucosidase and $\alpha$-amylase enzyme inhibitory effects of Andrographis paniculata extract and andrographolide," Acta Biochimica Polonica, vol. 55, no. 2, pp. 391-398, 2008.

[28] W. F. Chiou, J. J. Lin, and C. F. Chen, "Andrographolide suppresses the expression of inducible nitric oxide synthase in macrophage and restores the vasoconstriction in rat aorta treated with lipopolysaccharide," British Journal of Pharmacology, vol. 125, no. 2, pp. 327-334, 1998.

[29] W.-F. Chiou, C.-F. Chen, and J.-J. Lin, "Mechanisms of suppression of inducible nitric oxide synthase (iNOS) expression in RAW 264.7 cells by andrographolide," British Journal of Pharmacology, vol. 129, no. 8, pp. 1553-1560, 2000.

[30] K. Sheeja, P. K. Shihab, and G. Kuttan, "Antioxidant and antiinflammatory activities of the plant Andrographis paniculata nees," Immunopharmacology and Immunotoxicology, vol. 28, no. 1, pp. 129-140, 2006.

[31] Y. C. Shen, C. F. Chen, and W. F. Chiou, "Andrographolide prevents oxygen radical production by human neutrophils: possible mechanism(s) involved in its anti-inflammatory effect," British Journal of Pharmacology, vol. 135, no. 2, pp. 399-406, 2002.

[32] Y.-C. Shen, C.-F. Chen, and W.-F. Chiou, "Suppression of rat neutrophil reactive oxygen species production and adhesion by the diterpenoid lactone andrographolide," Planta Medica, vol. 66, no. 4, pp. 314-317, 2000.

[33] C. Wiart, K. Kumar, M. Y. Yusof, H. Hamimah, Z. M. Fauzi, and M. Sulaiman, "Antiviral properties of ent-labdene diterpenes 
of Andrographis paniculata Nees, inhibitors of herpes simplex virus type 1," Phytotherapy Research, vol. 19, no. 12, pp. 10691070, 2005.

[34] P. Misra, N. L. Pal, P. Y. Guru, J. C. Katiyar, V. Srivastava, and J. S. Tandon, "Antimalarial activity of Andrographis paniculata (Kalmegh) against Plasmodium berghei NK 65 in Mastomys natalensis," International Journal of Pharmacognosy, vol. 30, no. 4, pp. 263-274, 1992.

[35] R. E. Kamdem, S. Sang, and C.-T. Ho, "Mechanism of the superoxide scavenging activity of neoandrographolide-a natural product from Andrographis paniculata nees," Journal of Agricultural and Food Chemistry, vol. 50, no. 16, pp. 4662-4665, 2002.

[36] R. P. Singh, S. Banerjee, and A. R. Rao, "Modulatory influence of Andrographis paniculata on mouse hepatic and extrahepatic carcinogen metabolizing enzymes and antioxidant status," Phytotherapy Research, vol. 15, no. 5, pp. 382-390, 2001.

[37] G. A. Akowuah, I. Zhari, and A. Mariam, "Analysis of urinary andrographolides and antioxidant status after oral administration of Andrographis paniculata leaf extract in rats," Food and Chemical Toxicology, vol. 46, no. 12, pp. 3616-3620, 2008.

[38] C. Y. Zhang and B. K. H. Tan, "Mechanisms of cardiovascular activity of Andrographis paniculata in the anaesthetized rat," Journal of Ethnopharmacology, vol. 56, no. 2, pp. 97-101, 1997.

[39] B.-H. Tan and A. Zhang, "Andrographis paniculata and the cardiovascular system," Oxidative Stress and Disease, vol. 14, pp. 441-456, 2004.

[40] S. S. Handa and A. Sharma, "Hepatoprotective activity of andrographolide from Andrographis paniculata against carbontetrachloride," The Indian Journal of Medical Research, vol. 92, pp. 276-283, 1990.

[41] S. S. Handa and A. Sharma, "Hepatoprotective activity of andrographolide against galactosamine and paracetamol intoxication in rats," Indian Journal of Medical Research, vol. 92, pp. 284-292, 1990.

[42] A. Kapil, I. B. Koul, S. K. Banerjee, and B. D. Gupta, "Antihepatoxic effects of major diterpenoid constituents of Andrographis paniculata," Biochemical Pharmacology, vol. 46, no. 1, pp. 182$185,1993$.

[43] R. Chander, V. Srivastava, J. S. Tandon, and N. K. Kapoor, "Antihepatotoxic activity of diterpenes of Andrographis paniculata (Kal-Megh) against Plasmodium berghei-induced hepatic damage in Mastomys natalensis," International Journal of Pharmacognosy, vol. 33, no. 2, pp. 135-138, 1995.

[44] N. Trivedi and U. M. Rawal, "Hepatoprotective and toxicological evaluation of Andrographis paniculata on severe liver damage," Indian Journal of Pharmacology, vol. 32, no. 5, pp. 288293, 2000.

[45] N. P. Trivedi and U. M. Rawal, "Hepatoprotective and antioxidant property of Andrographis paniculata (Nees) in BHC induced liver damage in mice," Indian Journal of Experimental Biology, vol. 39, no. 1, pp. 41-46, 2001.

[46] P. K. S. Visen, B. Saraswat, V. Vuksan, and B. N. Dhawan, "Effect of andrographolide on monkey hepatocytes against galactosamine induced cell toxicity: an in-vitro study," Journal of Complementary and Integrative Medicine, vol. 4, no. 1, article 10, 2007.

[47] B. Saraswat, P. K. S. Visen, G. K. Patnaik, and B. N. Dhawan, "Effect of andrographolide against galactosamine-induced hepatotoxicity," Fitoterapia, vol. 66, no. 5, pp. 415-420, 1995.

[48] B. R. Choudhury and M. K. Poddar, "Andrographolide and kalmegh (Andrographis paniculata) extract: in vivo and in vitro effect on hepatic lipid peroxidation," Methods and Findings in Experimental and Clinical Pharmacology, vol. 6, no. 9, pp. 481485, 1984.

[49] B. R. Choudhury, S. J. Haque, and M. K. Poddar, "In vivo and in vitro effects of kalmegh (Andrographis paniculata) extract and andrographolide on hepatic microsomal drug metabolizing enzymes," Planta Medica, vol. 53, no. 2, pp. 135-140, 1987.

[50] A. C. Rana and Y. Avadhoot, "Hepatoprotective effects of Andrograhphis paniculata against carbon tetrachloride-induced liver damage," Archives of Pharmacal Research, vol. 14, no. 1, pp. 9395, 1991.

[51] P. K. S. Visen, B. Shukia, G. K. Patnaik, and B. N. Dhawan, "Andrographolide protects rat hepatocytes against paracetamolinduced damage," Journal of Ethnopharmacology, vol. 40, no. 2, pp. 131-136, 1993.

[52] B. Shukla, P. K. S. Visen, G. K. Patnaik, and B. N. Dhawan, "Choleretic effect of andrographolide in rats and guinea pigs," Planta Medica, vol. 58, no. 2, pp. 146-149, 1992.

[53] C. Calabrese, S. H. Berman, J. G. Babish et al., "A phase I trial of andrographolide in HIV positive patients and normal volunteers," Phytotherapy Research, vol. 14, no. 5, pp. 333-338, 2000.

[54] T. Otake, H. Mori, M. Morimoto et al., "Screening of Indonesian plant extracts for anti-human immunodeficiency virus-type 1 (HIV-1) activity," Phytotherapy Research, vol. 9, no. 1, pp. 6-10, 1995.

[55] R. S. Chang, L. Ding, C. Gai-Qing, P. Qi-Choa, Z. Ze-Lin, and K. M. Smith, "Dehydroandrographolide succinic acid monoester as an inhibitor against the human immunodeficiency virus (43225)," Proceedings of the Society for Experimental Biology and Medicine, vol. 197, no. 1, pp. 59-66, 1991.

[56] A. Basak, S. Cooper, A. G. Roberge, U. K. Banik, M. Chrétien, and N. G. Seidah, "Inhibition of proprotein convertases-1, -7 and furin by diterpines of Andrographis paniculata and their succinoyl esters," Biochemical Journal, vol. 338, no. 1, pp. 107113, 1999.

[57] M. I. Iruretagoyena, J. A. Tobar, P. A. González et al., "Andrographolide interferes with $\mathrm{T}$ cell activation and reduces experimental autoimmune encephalomyelitis in the mouse," Journal of Pharmacology and Experimental Therapeutics, vol. 312, no. 1, pp. 366-372, 2005.

[58] M. A. Akbarsha and P. Murugaian, "Aspects of the male reproductive toxicity/male antifertility property of andrographolide in albino rats: effect on the testis and the cauda epididymidal spermatozoa," Phytotherapy Research, vol. 14, no. 6, pp. 432-435, 2000.

[59] A. Niranjan, S. K. Tewari, and A. Lehri, "Biological activities of Kalmegh (Andrographis paniculata Nees) and its active principles-A review," Indian Journal of Natural Products and Resources, vol. 1, no. 2, pp. 125-135, 2010.

[60] Z. Wu, P. H. Raven, D. Y. Hong, and M. B. Garden, Flora of China: Cucurbitaceae Through Valerianaceae with Annonaceae and Berberidaceae, Science Press, Beijing, China, 1996.

[61] G. K. Benoy, D. K. Animesh, M. Aninda, D. K. Priyanka, and H. Sandip, "An overview on Andrographis paniculata (burm. F.) Nees," International Journal of Research in Ayurveda and Pharmacy, vol. 3, no. 6, pp. 752-760, 2012.

[62] C. Boopathi, "Andrographis spp.: a source of bitter compounds for medicinal use," Ancient Science of Life, vol. 19, no. 3-4, pp. 164-168, 2000.

[63] D. Anju, G. Jugnu, S. Kavitha, N. Arjun, and D. Sandeep, "A review on medicinal prospective of Andrographis paniculata 
Nees," Journal of Pharmaceutical and Scientific Innovation, vol. 1, no. 1, pp. 1-4, 2012.

[64] S. Patidar, A. S. Gontia, A. Upadhyay, and P. S. Nayak, "Biochemical constituents in Kalmegh (Andrographis paniculata Nees.) under various row spacing's and nitrogen levels," World Applied Sciences Journal, vol. 15, no. 8, pp. 1095-1099, 2011.

[65] S. Bhattacharya, S. Puri, A. Jamwal, and S. Sharma, "Studies on seed germination and seedling growth in Kalmegh (Andrographis paniculata Wall. Ex Nees) under abiotic stress conditions," International Journal of Science, Environment and Technology, vol. 1, no. 3, pp. 197-204, 2012.

[66] G. Gnanasekaran and G. V. S. Murthy, "Lectotypifications in andrographis (Acanthaceae)," Rheedea, vol. 22, no. 2, pp. 77-79, 2012.

[67] Y. K. Rao, A. G. Damu, A. J. Rao et al., "Flavonoids from Andrographis viscosula," Chemical and Pharmaceutical Bulletin, vol. 51, no. 12, pp. 1374-1376, 2003.

[68] B. Parixit, C. Bharath, N. Rajarajeshwari, and S. Ganapaty, "The genus Andrographis-a review," International Journal of Pharmaceutical Sciences, vol. 4, no. 1, pp. 1835-1856, 2012.

[69] M. Saggoo and S. Bir, "Meiotic studies in certain members of family Acanthaceae from South India," The Journal of the Indian Botanical Society, vol. 65, no. 3, pp. 310-315, 1986.

[70] S. K. Roy and P. Datta, "Chromosomal biotypes of Andrographis paniculata in India and Bangladesh," Cytologia, vol. 53, no. 2, pp. 369-378, 1988.

[71] S. K. Mishra, N. S. Sangwan, and R. S. Sangwan, "Andrographis paniculata (Kalmegh): a review," Pharmacognosy Reviews, vol. 1, no. 2, pp. 283-298, 2007.

[72] T.-S. Wu, H.-J. Chern, A. G. Damu et al., "Flavonoids and entlabdane diterpenoids from Andrographis paniculata and their antiplatelet aggregatory and vasorelaxing effects," Journal of Asian Natural Products Research, vol. 10, no. 1, pp. 17-24, 2008.

[73] USDA (United States Department of Agriculture), RS (Agricultural Research Service), NGRP (National Genetic Resources Program), and GRIN (Germplasm Resources Information Network), “GRIN Taxonomy for Plants," April 2014, http://www .ars-grin.gov/cgi-bin/npgs/html/taxon.pl?414228.

[74] Tropicos.org, "Andrographis paniculata (Burm. f.) Wall. ex Nees,” 2014, http://www.tropicos.org/Name/100007.

[75] A. Valdiani, M. A. Kadir, S. G. Tan, D. Talei, M. P. Abdullah, and S. Nikzad, "Nain-e havandi andrographis paniculata present yesterday, absent today: a plenary review on underutilized herb of Iran's pharmaceutical plants," Molecular Biology Reports, vol. 39, no. 5, pp. 5409-5424, 2012.

[76] M. Sharma and R. Sharma, "Identification, purification and quantification of andrographolide from Andrographis paniculata (burm. F.) Nees by HPTLC at different stages of life cycle of crop," Journal of Current Chememical and Pharmaceutical Sciences, vol. 3, no. 1, pp. 23-32, 2013.

[77] M. Borhanuddin, M. Shamsuzzoha, and A. H. Hussain, "Hypoglycaemic effects of Andrographis paniculata Nees on nondiabetic rabbits," Bangladesh Medical Research Council Bulletin, vol. 20, no. 1, pp. 24-26, 1994.

[78] S. Madav, H. C. Tripathi, and S. K. Mishra, "Analgesic, antipyretic and antiulcerogenic effects of andrographolide," Indian Journal of Pharmaceutical Sciences, vol. 57, no. 3, pp. 121-125, 1995.

[79] K. Sheeja, C. Guruvayoorappan, and G. Kuttan, "Antiangiogenic activity of Andrographis paniculata extract and andrographolide," International Immunopharmacology, vol. 7, no. 2, pp. 211-221, 2007.
[80] V. L. N. Reddy, S. M. Reddy, V. Ravikanth et al., "A new bisandrographolide ether from Andrographis paniculata nees and evaluation of anti-HIV activity," Natural Product Research, vol. 19, no. 3, pp. 223-230, 2005.

[81] P. Thisoda, N. Rangkadilok, N. Pholphana, L. Worasuttayangkurn, S. Ruchirawat, and J. Satayavivad, "Inhibitory effect of Andrographis paniculata extract and its active diterpenoids on platelet aggregation," European Journal of Pharmacology, vol. 553, no. 1-3, pp. 39-45, 2006.

[82] M.-D. Shi, H.-H. Lin, Y.-C. Lee, J.-K. Chao, R.-A. Lin, and J.-H. Chen, "Inhibition of cell-cycle progression in human colorectal carcinoma Lovo cells by andrographolide," Chemico-Biological Interactions, vol. 174, no. 3, pp. 201-210, 2008.

[83] K. Sheeja and G. Kuttan, "Activation of cytotoxic T lymphocyte responses and attenuation of tumor growth in vivo by Andrographis paniculata extract and andrographolide," Immunopharmacology and Immunotoxicology, vol. 29, no. 1, pp. 81-93, 2007.

[84] L. Ji, T. Liu, J. Liu, Y. Chen, and Z. Wang, "Andrographolide inhibits human hepatoma-derived Hep3B cell growth through the activation of c-Jun N-terminal kinase," Planta Medica, vol. 73, no. 13, pp. 1397-1401, 2007.

[85] S. D. Manikam and J. Stanslas, "Andrographolide inhibits growth of acute promyelocytic leukaemia cells by inducing retinoic acid receptor-independent cell differentiation and apoptosis," Journal of Pharmacy and Pharmacology, vol. 61, no. 5, pp. 69-78, 2009.

[86] F.-P. Liang, C.-H. Lin, C.-D. Kuo, H.-P. Chao, and S.-L. Fu, "Suppression of v-Src transformation by andrographolide via degradation of the v-Src protein and attenuation of the Erk signaling pathway," Journal of Biological Chemistry, vol. 283, no. 8, pp. 5023-5033, 2008.

[87] C.-G. Jiang, J.-B. Li, F.-R. Liu, T. Wu, M. Yu, and H.-M. Xu, "Andrographolide inhibits the adhesion of gastric cancer cells to endothelial cells by blocking E-selectin expression," Anticancer Research, vol. 27, no. 4 B, pp. 2439-2447, 2007.

[88] M.-D. Shi, H.-H. Lin, T.-A. Chiang et al., "Andrographolide could inhibit human colorectal carcinoma Lovo cells migration and invasion via down-regulation of MMP-7 expression," Chemico-Biological Interactions, vol. 180, no. 3, pp. 344-352, 2009.

[89] Y.-C. Lee, H.-H. Lin, C.-H. Hsu, C.-J. Wang, T.-A. Chiang, and J.-H. Chen, "Inhibitory effects of andrographolide on migration and invasion in human non-small cell lung cancer A549 cells via down-regulation of PI3K/Akt signaling pathway," European Journal of Pharmacology, vol. 632, no. 1-3, pp. 23-32, 2010.

[90] R. A. Burgos, K. Seguel, M. Perez et al., "Andrographolide inhibits IFN- $\gamma$ and IL-2 cytokine production and protects against cell apoptosis," Planta Medica, vol. 71, no. 5, pp. 429434, 2005.

[91] J. Zhou, C.-N. Ong, G.-M. Hur, and H.-M. Shen, "Inhibition of the JAK-STAT3 pathway by andrographolide enhances chemosensitivity of cancer cells to doxorubicin," Biochemical Pharmacology, vol. 79, no. 9, pp. 1242-1250, 2010.

[92] X. F. Zhang and B. K. H. Tan, "Antihyperglycaemic and antioxidant properties of Andrographis paniculata in normal and diabetic rats," Clinical and Experimental Pharmacology and Physiology, vol. 27, no. 5-6, pp. 358-363, 2000.

[93] R. Subramanian, M. Z. Asmawi, and A. Sadikun, "Effect of andrographolide and ethanol extract of Andrographis paniculata on liver glycolytic, gluconeogenic, and lipogenic enzymes in a type 2 diabetic rat model," Pharmaceutical Biology, vol. 46, no. 10-11, pp. 772-780, 2008. 
[94] R. Subramanian, M. Z. Asmawi, and A. Sadikun, "Effect of ethanolic extract of Andrographis paniculata (Burm. F.) nees on a combination of fat-fed diet and low dose streptozotocin induced chronic insulin resistance in rats," Diabetologia Croatica, vol. 37, no. 1, pp. 13-22, 2008.

[95] T. Wang, B. Liu, W. Zhang, B. Wilson, and J.-S. Hong, "Andrographolide reduces inflammation-mediated dopaminergic neurodegeneration in mesencephalic neuron-glia cultures by inhibiting microglial activation," Journal of Pharmacology and Experimental Therapeutics, vol. 308, no. 3, pp. 975-983, 2004.

[96] M. A. Hidalgo, A. Romero, J. Figueroa et al., "Andrographolide interferes with binding of nuclear factor- $\kappa \mathrm{B}$ to DNA in HL-60derived neutrophilic cells," British Journal of Pharmacology, vol. 144, no. 5, pp. 680-686, 2005.

[97] J. Li, L. Luo, X. Wang, B. Liao, and G. Li, "Inhibition of NF$\kappa \mathrm{B}$ expression and allergen-induced airway inflammation in a mouse allergic asthma model by andrographolide," Cellular \& Molecular Immunology, vol. 6, no. 5, pp. 381-385, 2009.

[98] Z. Bao, S. Guan, C. Cheng et al., "A novel antiinflammatory role for andrographolide in asthma via inhibition of the nuclear factor- $\kappa \mathrm{b}$ pathway," The American Journal of Respiratory and Critical Care Medicine, vol. 179, no. 8, pp. 657-665, 2009.

[99] L.-H. Qin, L. Kong, G.-J. Shi, Z.-T. Wang, and B.-X. Ge, "Andrographolide inhibits the production of TNF- $\alpha$ and interleukin12 in lipopolysaccharide-stimulated macrophages: role of mitogen-activated protein kinases," Biological and Pharmaceutical Bulletin, vol. 29, no. 2, pp. 220-224, 2006.

[100] W. Parichatikanond, C. Suthisisang, P. Dhepakson, and A. Herunsalee, "Study of anti-inflammatory activities of the pure compounds from Andrographis paniculata (burm.f.) Nees and their effects on gene expression," International Immunopharmacology, vol. 10, no. 11, pp. 1361-1373, 2010.

[101] H.-C. Ko, B.-L. Wei, and W.-F. Chiou, "The effect of medicinal plants used in Chinese folk medicine on RANTES secretion by virus-infected human epithelial cells," Journal of Ethnopharmacology, vol. 107, no. 2, pp. 205-210, 2006.

[102] J.-X. Chen, H.-J. Xue, W.-C. Ye et al., "Activity of andrographolide and its derivatives against influenza virus in vivo and in vitro," Biological and Pharmaceutical Bulletin, vol. 32, no. 8, pp. 1385-1391, 2009.

[103] J. Sinha, S. Mukhopadhyay, N. Das, and M. K. Basu, “Targeting of liposomal andrographolide to L. donovani-infected macrophages in vivo," Drug Delivery, vol. 7, no. 4, pp. 209-213, 2000.

[104] S. Yang, A. M. Evens, S. Prachand et al., "Mitochondrialmediated apoptosis in lymphoma cells by the diterpenoid lactone andrographolide, the active component of Andrographis paniculata," Clinical Cancer Research, vol. 16, no. 19, pp. 4755$4768,2010$.

[105] J. Zhou, G.-D. Lu, C.-S. Ong, C.-N. Ong, and H.-M. Shen, "Andrographolide sensitizes cancer cells to TRAIL-induced apoptosis via p53-mediated death receptor 4 up-regulation," Molecular Cancer Therapeutics, vol. 7, no. 7, pp. 2170-2180, 2008.

[106] K. Sheeja and G. Kuttan, "Protective effect of Andrographis paniculata and andrographolide on cyclophosphamide-induced urothelial toxicity," Integrative Cancer Therapies, vol. 5, no. 3, pp. 244-251, 2006.

[107] A. Y. H. Woo, M. M. Y. Waye, S. K. W. Tsui, S. T. W. Yeung, and C. H. K. Cheng, "Andrographolide up-regulates cellularreduced glutathione level and protects cardiomyocytes against hypoxia/reoxygenation injury," Journal of Pharmacology and Experimental Therapeutics, vol. 325, no. 1, pp. 226-235, 2008.
[108] T.-Y. Lee, K.-C. Lee, and H.-H. Chang, "Modulation of the cannabinoid receptors by andrographolide attenuates hepatic apoptosis following bile duct ligation in rats with fibrosis," Apoptosis, vol. 15, no. 8, pp. 904-914, 2010.

[109] A. Panossian, T. Davtyan, N. Gukassyan et al., "Effect of andrographolide and Kan Jang-fixed combination of extract SHA10 and extract SHE-3-on proliferation of human lymphocytes, production of cytokines and immune activation markers in the whole blood cells culture," Phytomedicine, vol. 9, no. 7, pp. 598605, 2002.

[110] R. A. Burgos, M. A. Hidalgo, J. Monsalve, T. P. Labranche, P. Eyre, and J. L. Hancke, "14-Deoxyandrographolide as a platelet activating factor antagonist in bovine neutrophils," Planta Medica, vol. 71, no. 7, pp. 604-608, 2005.

[111] Y. Xu, A. Chen, S. Fry, R. A. Barrow, R. L. Marshall, and T. K. S. Mukkur, "Modulation of immune response in mice immunised with an inactivated Salmonella vaccine and gavaged with Andrographis paniculata extract or andrographolide," International Immunopharmacology, vol. 7, no. 4, pp. 515-523, 2007.

[112] M. D. Carretta, P. Alarcón, E. Jara et al., "Andrographolide reduces IL-2 production in T-cells by interfering with NFAT and MAPK activation," European Journal of Pharmacology, vol. 602, no. 2-3, pp. 413-421, 2009.

[113] S. R. Naik and A. Hule, "Evaluation of immunomodulatory activity of an extract of andrographolides from Andographis paniculata," Planta Medica, vol. 75, no. 8, pp. 785-791, 2009.

[114] W. Wang, J. Wang, S.-F. Dong et al., "Immunomodulatory activity of andrographolide on macrophage activation and specific antibody response," Acta Pharmacologica Sinica, vol. 31, no. 2, pp. 191-201, 2010.

[115] T.-P. Lin, S.-Y. Chen, P.-D. Duh, L.-K. Chang, and Y.-N. Liu, "Inhibition of the Epstein-Barr virus lytic cycle by andrographolide," Biological and Pharmaceutical Bulletin, vol. 31, no. 11, pp. 2018-2023, 2008.

[116] S.-K. Hung, L.-C. Hung, C.-D. Kuo et al., "Andrographolide sensitizes Ras-transformed cells to radiation in vitro and in vivo," International Journal of Radiation Oncology Biology Physics, vol. 77, no. 4, pp. 1232-1239, 2010.

[117] P. K. Singha, S. Roy, and S. Dey, "Protective activity of andrographolide and arabinogalactan proteins from Andrographis paniculata Nees. against ethanol-induced toxicity in mice," Journal of Ethnopharmacology, vol. 111, no. 1, pp. 13-21, 2007.

[118] J. Batkhuu, K. Hattori, F. Takano, S. Fushiya, K.-I. Oshiman, and Y. Fujimiya, "Suppression of NO production in activated macrophages in vitro and ex vivo by neoandrographolide isolated from Andrographis paniculata," Biological and Pharmaceutical Bulletin, vol. 25, no. 9, pp. 1169-1174, 2002.

[119] J. Liu, Z.-T. Wang, L.-L. Ji, and B.-X. Ge, "Inhibitory effects of neoandrographolide on nitric oxide and prostaglandin E2 production in LPS-stimulated murine macrophage," Molecular and Cellular Biochemistry, vol. 298, no. 1-2, pp. 49-57, 2007.

[120] P. H. Pfisterer, J. M. Rollinger, L. Schyschka, A. Rudy, A. M. Vollmar, and H. Stuppner, "Neoandrographolide from Andrographis paniculata as a potential natural chemosensitizer," Planta Medica, vol. 76, no. 15, pp. 1698-1700, 2010.

[121] A. Sule, Q. U. Ahmed, O. A. Samah et al., "Bioassay guided isolation of antibacterial compounds from Andrographis paniculata," The American Journal of Applied Sciences, vol. 8, no. 6, pp. 525$534,2011$.

[122] Q. U. Ahmed, O. A. Samah, and A. Sule, "Andrographis paniculata (Burm. f) Wall. ex Ness: a potent antibacterial plant," in 
Antimicrobial Agents, V. Bobbarala, Ed., pp. 345-360, InTech, 2012.

[123] A. Sule, Q. U. Ahmed, J. Latip et al., "Antifungal activity of Andrographis paniculata extracts and active principles against skin pathogenic fungal strains in vitro," Pharmaceutical Biology, vol. 50, no. 7, pp. 850-856, 2012.

[124] D. N. Roy, S. Mandal, G. Sen, S. Mukhopadhyay, and T. Biswas, "14-Deoxyandrographolide desensitizes hepatocytes to tumour necrosis factor-alpha-induced apoptosis through calciumdependent tumour necrosis factor receptor superfamily member 1A release via the NO/cGMP pathway," British Journal of Pharmacology, vol. 160, no. 7, pp. 1823-1843, 2010.

[125] R. A. Burgos, M. Loyola, M. A. Hidalgo, T. P. Labranche, and J. L. Hancke, "Effect of 14-deoxyandrographolide on calciummediated rat uterine smooth muscle contractility," Phytotherapy Research, vol. 17, no. 9, pp. 1011-1015, 2003.

[126] C. Y. Zhang and B. K. H. Tan, "Effects of 14-deoxyandrographolide and 14-deoxy-11,12-didehydroandrographolide on nitric oxide production in cultured human endothelial cells," Phytotherapy Research, vol. 13, no. 2, pp. 157-159, 1999.

[127] C. Y. Zhang and B. K. H. Tan, "Vasorelaxation of rat thoracic aorta caused by 14-deoxyandrographolide," Clinical and Experimental Pharmacology and Physiology, vol. 25, no. 6, pp. 424429, 1998.

[128] M.-J. Lee, Y. K. Rao, K. Chen, Y.-C. Lee, Y.-S. Chung, and Y.-M. Tzeng, "Andrographolide and 14-deoxy-11,12-didehydroandrographolide from Andrographis paniculata attenuate high glucose-induced fibrosis and apoptosis in murine renal mesangeal cell lines," Journal of Ethnopharmacology, vol. 132, no. 2, pp. 497505,2010 .

[129] G. A. Akowuah, I. Zhari, A. Mariam, and M. F. Yam, "Absorption of andrographolides from Andrographis paniculata and its effect on $\mathrm{CCl}_{4}$-induced oxidative stress in rats," Food and Chemical Toxicology, vol. 47, no. 9, pp. 2321-2326, 2009.

[130] M. Tan, M. Kuroyanagi, S. Sulaiman, N. Najimudin, and T. T. Muhammad, "Cytotoxic activities of major diterpenoid constituents of Andrographis paniculata in a panel of human tumor cell lines," Pharmaceutical Biology, vol. 43, no. 6, pp. 501508, 2005.

[131] N. Yoopan, P. Thisoda, N. Rangkadilok et al., "Cardiovascular effects of 14-Deoxy-11,12-didehydroandrographolide and Andrographis paniculata extracts," Planta Medica, vol. 73, no. 6, pp. 503-511, 2007.

[132] R. Subramanian, M. Z. Asmawi, and A. Sadikun, "A bitter plant with a sweet future? A comprehensive review of an oriental medicinal plant: Andrographis paniculata," Phytochemistry Reviews, vol. 11, no. 1, pp. 39-75, 2012.

[133] X. He, X. Zeng, H. Hu, and Y. Wu, "Cytotoxic biotransformed products from andrographolide by Rhizopus stolonifer ATCC 12939," Journal of Molecular Catalysis B: Enzymatic, vol. 62, no. 3-4, pp. 242-247, 2010.

[134] Y.-H. Shen, R.-T. Li, W.-L. Xiao, Z.-W. Lin, Q.-S. Zhao, and H.-D. Sun, "ent-labdane diterpenoids from Andrographis paniculata," Journal of Natural Products, vol. 69, no. 3, pp. 319-322, 2006.

[135] L.-L. Ji, Z. Wang, F. Dong, W.-B. Zhang, and Z.-T. Wang, "Andrograpanin, a compound isolated from anti-inflammatory traditional Chinese medicine Andrographis paniculata, enhances chemokine SDF- $1 \alpha$-induced leukocytes chemotaxis," Journal of Cellular Biochemistry, vol. 95, no. 5, pp. 970-978, 2005.
[136] J. Liu, Z.-T. Wang, and B.-X. Ge, "Andrograpanin, isolated from Andrographis paniculata, exhibits anti-inflammatory property in lipopolysaccharide-induced macrophage cells through down-regulating the p38 MAPKs signaling pathways," International Immunopharmacology, vol. 8, no. 7, pp. 951-958, 2008.

[137] S. Lala, A. K. Nandy, S. B. Mahato, and M. K. Basu, "Delivery in vivo of 14-deoxy-11-oxoandrographolide, an antileishmanial agent, by different drug carriers," Indian Journal of Biochemistry and Biophysics, vol. 40, no. 3, pp. 169-174, 2003.

[138] L. Chen, H. Zhu, R. Wang, K. Zhou, Y. Jing, and F. Qiu, "entlabdane diterpenoid lactone stereoisomers from Andrographis paniculata," Journal of Natural Products, vol. 71, no. 5, pp. 852$855,2008$.

[139] G.-C. Wang, Y. Wang, I. D. Williams et al., "Andrographolactone, a unique diterpene from Andrographis paniculata," Tetrahedron Letters, vol. 50, no. 34, pp. 4824-4826, 2009.

[140] P. L. Smith, K. N. Maloney, R. G. Pothen, J. Clardy, and D. E. Clapham, "Bisandrographolide from Andrographis paniculata activates TRPV4 channels," The Journal of Biological Chemistry, vol. 281, no. 40, pp. 29897-29904, 2006.

[141] M. Arifullah, N. D. Namsa, M. Mandal, K. K. Chiruvella, P. Vikrama, and G. R. Gopal, "Evaluation of anti-bacterial and anti-oxidant potential of andrographolide and echiodinin isolated from callus culture of Andrographis paniculata Nees," Asian Pacific Journal of Tropical Biomedicine, vol. 3, no. 8, pp. 604-610, 2013.

[142] L.-X. Chen, H. He, G.-Y. Xia, K.-L. Zhou, and F. Qiu, "A new flavonoid from the aerial parts of Andrographis paniculata," Natural Product Research, vol. 28, no. 3, pp. 138-143, 2014.

[143] V. K. Dua, V. P. Ojha, R. Roy et al., "Anti-malarial activity of some xanthones isolated from the roots of Andrographis paniculata," Journal of Ethnopharmacology, vol. 95, no. 2-3, pp. 247-251, 2004.

[144] L.-X. Chen, F. Qiu, H. Wei, G.-X. Qu, and X.-S. Yao, "Nine new ent-labdane diterpenoids from the aerial parts of Andrographis paniculata," Helvetica Chimica Acta, vol. 89, no. 11, pp. 26542664, 2006.

[145] T. Fujita, R. Fujitani, Y. Takeda et al., "On the diterpenoids of Andrographis paniculata: X-ray crystallographic analysis of andrographolide and structure determination of new minor diterpenoids," Chemical and Pharmaceutical Bulletin, vol. 32, no. 6, pp. 2117-2125, 1984.

[146] S. Pramanick, S. Banerjee, B. Achari et al., "Andropanolide and isoandrographolide, minor diterpenoids from Andrographis paniculata: structure and X-ray crystallographic analysis," Journal of Natural Products, vol. 69, no. 3, pp. 403-405, 2006.

[147] Y. K. Rao, G. Vimalamma, C. V. Rao, and Y.-M. Tzeng, "Flavonoids and andrographolides from Andrographis paniculata," Phytochemistry, vol. 65, no. 16, pp. 2317-2321, 2004.

[148] M. K. Reddy, M. V. B. Reddy, D. Gunasekar, M. M. Murthy, C. Caux, and B. Bodo, "A flavone and an unusual 23-carbon terpenoid from Andrographis paniculata," Phytochemistry, vol. 62, no. 8, pp. 1271-1275, 2003.

[149] S. K. Seth, S. Banerjee, and T. Kar, "Crystal structure and DFT calculations of andrographiside," Journal of Molecular Structure, vol. 965, no. 1-3, pp. 45-49, 2010.

[150] C. Xu, G. X. Chou, and Z. T. Wang, "A new diterpene from the leaves of Andrographis paniculata Nees," Fitoterapia, vol. 81, no. 6, pp. 610-613, 2010.

[151] K.-L. Zhou, L.-X. Chen, Y.-L. Zhuang, N.-L. Wang, X.-S. Yao, and F. Qiu, "Two new ent-labdane diterpenoid glycosides from 
the aerial parts of Andrographis paniculata," Journal of Asian Natural Products Research, vol. 10, no. 10, pp. 939-943, 2008.

[152] Q. Y. Zou, N. Li, C. Dan, W. L. Deng, S. L. Peng, and L. S. Ding, "A new ent-labdane diterpenoid from Andrographis paniculata," Chinese Chemical Letters, vol. 21, no. 9, pp. 1091-1093, 2010.

[153] M. K. Bhan, A. K. Dhar, S. Khan, S. K. Lattoo, K. K. Gupta, and D. K. Choudhary, "Screening and optimization of Andrographis paniculata (Burm.f.) Nees for total andrographolide content, yield and its components," Scientia Horticulturae, vol. 107, no. 4, pp. 386-391, 2006.

[154] S. Nemade, N. Mohod, S. Wankhade, and J. Paturde, "Effect of planting and harvesting dates on yield and quality of kalmegh (Andrographis paniculata)," Journal of Medicinal and Aromatic Plant Sciences, vol. 25, no. 4, pp. 981-983, 2003.

[155] M. Singh, A. Singh, R. Tripathi et al., "Growth behavior, biomass and diterpenoid lactones production in Kalmegh (Andrographis paniculata Nees.) strains at different population densities," Agricultural Journal, vol. 6, no. 3, pp. 115-118, 2011.

[156] R. Parashar, A. Upadhyay, J. Singh, S. K. Diwedi, and N. A. Khan, "Morpho-physiological evaluation of Andrographis paniculata at different growth stages," World Journal of Agricultural Sciences, vol. 7, no. 2, pp. 124-127, 2011.

[157] D. Talei, A. Valdiani, M. P. Abdullah, and S. A. Hassan, "A rapid and effective method for dormancy breakage and germination of king of bitters (Andrographis paniculata Nees.) seeds," Maydica, vol. 57, no. 2, pp. 98-105, 2012.

[158] S. K. Lattoo, R. S. Dhar, S. Khan et al., "Comparative analysis of genetic diversity using molecular and morphometric markers in Andrographis paniculata (Burm. f.) Nees," Genetic Resources and Crop Evolution, vol. 55, no. 1, pp. 33-43, 2008.

[159] B. Kumar, S. K. Verma, and H. P. Singh, "Effect of temperature on seed germination parameters in Kalmegh (Andrographis paniculata Wall. ex Nees.)," Industrial Crops and Products, vol. 34, no. 1, pp. 1241-1244, 2011.

[160] R. N. Kumar, S. Chakraborty, and K. Nirmal, "Methods to break seed dormancy of Andrographis paniculata (Burm. f. Nees): an important medicinal herb of tropical Asia," Asian Journal of Experimental Biological Sciences, vol. 2, no. 1, pp. 143-146, 2011.

[161] A. Kataky and P. Handique, "Micropropagation and screening of antioxidant potential of Andrographis paniculata (Burm. f) Nees," Journal of Hill Agriculture, vol. 1, no. 1, pp. 13-18, 2010.

[162] K. P. Martin, "Plant regeneration protocol of medicinally important Andrographis paniculata (Burm. f.) Wallich ex Nees via somatic embryogenesis," In Vitro Cellular and Developmental Biology-Plant, vol. 40, no. 2, pp. 204-209, 2004.

[163] J. Purkayastha, T. Sugla, A. Paul, S. Solleti, and L. Sahoo, "Rapid in vitro multiplication and plant regeneration from nodal explants of Andrographis paniculata: a valuable medicinal plant," In Vitro Cellular \& Developmental Biology_Plant, vol. 44, no. 5, pp. 442-447, 2008.

[164] V. S. Dandin and H. N. Murthy, "Regeneration of Andrographis paniculata Nees: analysis of genetic fidelity and andrographolide content in micropropagated plants," African Journal of Biotechnology, vol. 11, no. 61, pp. 12464-12471, 2012.

[165] S. Gandi, K. Rao, B. Chodisetti, and A. Giri, "Elicitation of andrographolide in the suspension cultures of Andrographis paniculata," Applied Biochemistry and Biotechnology, vol. 168, no. 7, pp. 1729-1738, 2012.

[166] B. Bowes, "The fine structure of wall modifications and associated structures in callus tissue of Andrographis paniculata Nees," New Phytologist, vol. 68, no. 3, pp. 619-626, 1969.
[167] P. R. Behera, P. Nayak, D. P. Barik, T. R. Rautray, M. Thirunavoukkarasu, and P. K. Chand, "ED-XRF spectrometric analysis of comparative elemental composition of in vivo and in vitro roots of Andrographis paniculata (Burm.f.) Wall. ex Nees-a multi-medicinal herb," Applied Radiation and Isotopes, vol. 68, no. 12, pp. 2229-2236, 2010.

[168] M. A. F. Jalal, K. H. Overton, and D. S. Rycroft, "Formation of three new flavones by differentiating callus cultures of Andrographis paniculata," Phytochemistry, vol. 18, no. 1, pp. 149151, 1979.

[169] W. Deng, "Outline of current clinical and pharmacological research on Andrographis paniculata in China," Newsletters of Chinese Herbal Medicine, vol. 10, pp. 27-31, 1978.

[170] O. Sareer, A. Ahad, and S. Umar, "Prophylactic and lenitive effects of Andrographis paniculata against common human ailments: an exhaustive and comprehensive reappraisal," Journal of Pharmaceutical Research and Opinion, vol. 2, no. 10, pp. 138$162,2012$.

[171] C. Xu, G.-X. Chou, C.-H. Wang, and Z.-T. Wang, "Rare noriridoids from the roots of Andrographis paniculata," Phytochemistry, vol. 77, pp. 275-279, 2012.

[172] X.-Q. Zhang, G.-C. Wang, W.-C. Ye, Q. Li, G.-X. Zhou, and X.-S. Yao, "New diterpenoids from Andrographis paniculata (Burm. f.) Nees," Journal of Integrative Plant Biology, vol. 48, no. 9, pp. 1122-1125, 2006.

[173] J. Hancke, R. Burgos, D. Caceres, and G. Wikman, "A doubleblind study with a new monodrug Kan Jang: decrease of symptoms and improvement in the recovery from common colds," Phytotherapy Research, vol. 9, no. 8, pp. 559-562, 1995.

[174] D. D. Cáceres, J. L. Hancke, R. A. Burgos, and G. K. Wikman, "Prevention of common colds with Andrographis paniculata dried extract. A pilot double blind trial," Phytomedicine, vol. 4, no. 2, pp. 101-104, 1997.

[175] J. Melchior, S. Palm, and G. Wikman, "Controlled clinical study of standardized Andrographis paniculata extract in common cold-a pilot trial," Phytomedicine, vol. 3, no. 4, pp. 315-318, 1997.

[176] A. A. Abu-Ghefreh, H. Canatan, and C. I. Ezeamuzie, "In vitro and in vivo anti-inflammatory effects of andrographolide," International Immunopharmacology, vol. 9, no. 3, pp. 313-318, 2009.

[177] S. Habtemariam, "Andrographolide inhibits the tumour necrosis factor- $\alpha$-induced upregulation of ICAM-1 expression and endothelial-monocyte adhesion," Phytotherapy Research, vol.12, no. 1, pp. 37-40, 1998.

[178] S. F. Liu and A. B. Malik, "NF- $\kappa$ B activation as a pathological mechanism of septic shock and inflammation," The American Journal of Physiology - Lung Cellular and Molecular Physiology, vol. 290, no. 4, pp. L622-L645, 2006.

[179] A. M. Marrache, F. Gobeil Jr., S. G. Bernier et al., "Proinflammatory gene induction by platelet-activating factor mediated via its cognate nuclear receptor," The Journal of Immunology, vol. 169, no. 11, pp. 6474-6481, 2002.

[180] J. Pocock, C. Gómez-Guerrero, S. Harendza et al., "Differential activation of NF- $\kappa \mathrm{B}, \mathrm{AP}-1$, and C/EBP in endotoxintolerant rats: mechanisms for in vivo regulation of glomerular RANTES/CCL5 expression," The Journal of Immunology, vol. 170, no. 12, pp. 6280-6291, 2003.

[181] S. Madav, S. K. Tandan, J. Lal, and H. C. Tripathi, "Antiinflammatory activity of andrographolide," Fitoterapia, vol. 67, no. 5, pp. 452-458, 1996.

[182] B. Zhang, L. Yan, P. Zhou et al., "CHP1002, a novel andrographolide derivative, inhibits pro-inflammatory inducible 
nitric oxide synthase and cyclooxygenase-2 expressions in RAW264.7 macrophages via up-regulation of heme oxygenase1 expression," International Immunopharmacology, vol. 15, no. 2, pp. 289-295, 2013.

[183] W. Liu, W. Guo, L. Guo et al., "Andrographolide sulfonate ameliorates experimental colitis in mice by inhibiting Thl/Th17 response," International Immunopharmacology, vol. 20, no. 2, pp. 337-345, 2014.

[184] D. Kajaria, J. Ranjana, Y. B. Tripathi, and S. Tiwari, "In vitro a amylase and glucosidase inhibitory effect of ethanolic extract of antiasthmatic drug-Shirishadi," Journal of Advanced Pharmaceutical Technology and Research, vol. 4, no. 4, pp. 206-209, 2013.

[185] G. Reaven, “The metabolic syndrome or the insulin resistance syndrome? Different names, different concepts, and different goals," Endocrinology and Metabolism Clinics of North America, vol. 33, no. 2, pp. 283-303, 2004.

[186] W.-W. Chao and B.-F. Lin, "Isolation and identification of bioactive compounds in Andrographis paniculata (Chuanxinlian)," Chinese Medicine, vol. 5, article 17, pp. 1-15, 2010.

[187] A. W. Augustine, A. Narasimhan, M. Vishwanathan, and B. Karundevi, "Evaluation of antidiabetic property of Andrographis paniculata powder in high fat and sucrose-induced type-2 diabetic adult male rat," Asian Pacific Journal of Tropical Disease, vol. 4, supplement 1, pp. S140-S147, 2014.

[188] R. Gupta, K. G. Bajpai, S. Johri, and A. M. Saxena, "An overview of Indian novel traditional medicinal plants with anti-diabetic potentials," African Journal of Traditional, Complementary and Alternative Medicines, vol. 5, no. 1, pp. 1-17, 2008.

[189] Z. Zhang, J. Jiang, P. Yu, X. Zeng, J. W. Larrick, and Y. Wang, "Hypoglycemic and beta cell protective effects of andrographolide analogue for diabetes treatment," Journal of Translational Medicine, vol. 7, article 62, 2009.

[190] A. E. Nugroho, I. R. Rais, I. Setiawan et al., "Pancreatic effect of andrographolide isolated from Andrographis paniculata (Burm. f.) Nees," Pakistan Journal of Biological Sciences, vol. 17, no. 1, pp. 22-31, 2014.

[191] C. Zhang, L. Gui, Y. Xu, T. Wu, and D. Liu, "Preventive effects of andrographolide on the development of diabetes in autoimmune diabetic NOD mice by inducing immune tolerance," International Immunopharmacology, vol. 16, no. 4, pp. 451-456, 2013.

[192] A. E. Nugroho, G. Kusumaramdani, A. Widyaninggar, D. P. Anggoro, and S. Pramono, "Antidiabetic effect of combinations of n-hexane insoluble fraction of ethanolic extract of Andrographis paniculata with other traditional medicines," International Food Research Journal, vol. 21, no. 2, pp. 785-789, 2014.

[193] V. K. Verma, K. K. Sarwa, A. Kumar, and M. Zaman, "Comparison of hepatoprotective activity of Swertia chirayita and Andrographis paniculata plant of North-East India against $\mathrm{CCl}_{4}$ induced hepatotoxic rats," Journal of Pharmacy Research, vol. 7, no. 7, pp. 647-653, 2013.

[194] A. Leelarasamee, S. Trakulsomboon, and N. Sittisomwong, "Undetectable anti-bacterial activity of Andrographis paniculata (Burma) wall. ex ness," Journal of the Medical Association of Thailand, vol. 73, no. 6, pp. 299-304, 1990.

[195] K. Nakanishi, S. Sasaki, A. K. Kiang et al., "Phytochemical survey of Malaysian plants preliminary chemical and pharmacological screening," Chemical and Pharmaceutical Bulletin, vol. 13, no. 7, pp. 882-890, 1965.

[196] U. S. Mishra, A. Mishra, R. Kumari, P. N. Murthy, and B. S. Naik, "Antibacterial activity of ethanol extract of Andrographis paniculata," Indian Journal of Pharmaceutical Sciences, vol. 71, no. 4, pp. 436-438, 2009.

[197] P. K. Singha, S. Roy, and S. Dey, "Antimicrobial activity of Andrographis paniculata," Fitoterapia, vol. 74, no. 7-8, pp. 692-694, 2003.

[198] D. S. Fabricant and N. R. Farnsworth, "The value of plants used in traditional medicine for drug discovery," Environmental Health Perspectives, vol. 109, no. 1, pp. 69-75, 2001.

[199] A. Sule, Q. U. Ahmed, O. Samah, and M. Omar, "Screening for antibacterial activity of Andrographis paniculata used in Malaysian folkloric medicine: a possible alternative for the treatment of skin infections," Ethnobotanical Leaflets, vol. 2010, no. 4, pp. 445-456, 2010.

[200] A. Sule, Q. U. Ahmed, O. A. Samah, and M. N. Omar, "Bacteriostatic and bactericidal activities of Andrographis paniculata extracts on skin disease causing pathogenic bacteria," Journal of Medicinal Plants Research, vol. 5, no. 1, pp. 7-14, 2011.

[201] L. I. C. Tang, A. P. K. Ling, R. Y. Koh, S. M. Chye, and K. G. L. Voon, "Screening of anti-dengue activity in methanolic extracts of medicinal plants," BMC Complementary and Alternative Medicine, vol. 12, article 3, 2012.

[202] S. Fangkham, T. Ekalaksananan, C. Aromdee et al., "The effect of andrographolide on Human papillomavirus type 16 (HPV16) positive cervical cancer cells ( $\mathrm{SiHa}$ )," International Journal of Infectious Diseases, vol. 16, supplement 1, p. e80, 2012.

[203] C. Aromdee, S. Suebsasana, T. Ekalaksananan, C. Pientong, and S. Thongchai, "Stage of action of naturally occurring andrographolides and their semisynthetic analogues against herpes simplex virus type 1 in vitro," Planta Medica, vol. 77, no. 9, pp. 915-921, 2011.

[204] H. X. Xu, M. Wan, B. N. Loh, O. L. Kon, P. W. Chow, and K. Y. Sim, "Screening of traditional medicines for their inhibitory activity against HIV-1 protease," Phytotherapy Research, vol. 10, no. 3, pp. 207-210, 1996.

[205] S. Holt and L. Comac, Miracle Herbs: How Herbs Combine with Modern Medicine to Treat Cancer; Heart Disease, AIDS, and More, Kensington, Caro, Mich, USA, 1998.

[206] M. Z. Zaridah, S. Z. Idid, A. Wan Omar, and S. Khozirah, "In vitro antifilarial effects of three plant species against adult worms of subperiodic Brugia malayi," Journal of Ethnopharmacology, vol. 78, no. 1, pp. 79-84, 2001.

[207] Y. Padma, C. L. Narasimhudu, S. Devi, N. M. B. Natha, R. B. Naga, and G. H. Philip, "In vitro anthelmintic activity of Andrographis paniculata (burm.f.) nees," International Journal of Pharmaceutical Research and Developement, vol. 3, no. 3, pp. 202-205, 2011.

[208] A. Vojdani and J. Erde, "Regulatory T cells, a potent immunoregulatory target for CAM researchers: modulating tumor immunity, autoimmunity and alloreactive immunity (III)," Evidence-Based Complementary and Alternative Medicine, vol. 3, no. 3, pp. 309-316, 2006.

[209] V. S. P. K. Aditya, N. L. Kumar, and A. Mokkapati, "Evaluation of in vitro cytotoxicity of Andrographis paniculata, Duranta serratifolia and Albizzia lebbeck whole plant extracts by MTT assay against MCF-7 and HT-29 cell lines," Current Research in Microbiology and Biotechnology, vol. 2, no. 2, pp. 351-353, 2014.

[210] M. Geethangili, Y. K. Rao, S.-H. Fang, and Y.-M. Tzeng, "Cytotoxic constituents from Andrographis paniculata induce cell cycle arrest in Jurkat cells," Phytotherapy Research, vol. 22, no. 10, pp. 1336-1341, 2008. 
[211] H.-H. Lin, M.-D. Shi, H.-C. Tseng, and J.-H. Chen, "Andrographolide sensitizes the cytotoxicity of human colorectal carcinoma cells toward cisplatin via enhancing apoptosis pathways in vitro and in vivo," Toxicological Sciences, vol. 139, no. 1, pp. 108-120, 2014.

[212] C. Satyanarayana, D. S. Deevi, R. Rajagopalan, N. Srinivas, and S. Rajagopal, "DRF 3188 a novel semi-synthetic analog of andrographolide: cellular response to MCF 7 breast cancer cells," BMC Cancer, vol. 4, article 26, 2004.

[213] S. R. Jada, G. S. Subur, C. Matthews et al., "Semisynthesis and in vitro anticancer activities of andrographolide analogues," Phytochemistry, vol. 68, no. 6, pp. 904-912, 2007.

[214] E. Amroyan, E. Gabrielian, A. Panossian, G. Wikman, and H. Wagner, "Inhibitory effect of andrographolide from Andrographis paniculata on PAF-induced platelet aggregation," Phytomedicine, vol. 6, no. 1, pp. 27-31, 1999.

[215] O. Bukoye and A. Musbau, "Immune modulation potentials of aqueous extract of Andrographis paniculata leaves in male rat," Researcher, vol. 3, no. 1, pp. 48-57, 2011.

[216] K. Sheeja and G. Kuttan, “Andrographis paniculata downregulates proinflammatory cytokine production and augments cell mediated immune response in metastatic tumor-bearing mice," Asian Pacific Journal of Cancer Prevention, vol. 11, no. 3, pp. 723729, 2010.

[217] H. Zhao and W. Fang, "Protective effects of Andrographis paniculata Nees on post-infarction myocardium in experimental dogs," Journal of Tongji Medical University, vol. 10, no. 4, pp. 212217, 1990.

[218] H. Y. Zhao and W. Y. Fang, "Antithrombotic effects of Andrographis paniculata nees in preventing myocardial infarction," Chinese Medical Journal, vol. 104, no. 9, pp. 770-775, 1991.

[219] G. Zhi-ling, Z. Hua-yue, and Z. Xin-hua, “The effect of Andrographis Paniculata Nees (APN) in alleviating the myocardial ischemic reperfusion injury," Journal of Tongji Medical University, vol. 14, no. 1, pp. 49-51, 1994.

[220] G. Zhi-ling, Z. Hua-yue, and Z. Xin-hua, "An experimental study of the mechanism of Andrographis paniculata nees (APN) in alleviating the $\mathrm{Ca}^{2+}$-overloading in the process of myocardial ischemie reperfusion," Journal of Tongji Medical University, vol. 15, no. 4, pp. 205-208, 1995.

[221] Z.-L. Guo, H. Zhao, and L. Fu, "Protective effects of API0134 on myocardial ischemia and reperfusion injury," Journal of Tongji Medical University, vol. 16, no. 4, pp. 193-197, 1996.

[222] H. W. Wang, H. Y. Zhao, and S. Q. Xiang, "Effects of Andro graphis paniculata component on nitric oxide, endothelin and lipid peroxidation in experimental atherosclerotic rabbits," Chinese Journal of Integrated Traditional and Western Medicine, vol. 17, no. 9, pp. 547-549, 1997.

[223] D. W. Wang and H. Y. Zhao, "Prevention of atherosclerotic arterial stenosis and restenosis after angioplasty with Andrographis paniculata nees and fish oil. Experimental studies of effects and mechanisms," Chinese Medical Journal, vol. 107, no. 6, pp. 464470, 1994.

[224] C. Zhang, M. Kuroyangi, and B. K. H. Tan, "Cardiovascular activity of 14-deoxy-11,12-didehydroandrographolide in the anaesthetised rat and isolated right atria," Pharmacological Research, vol. 38, no. 6, pp. 413-418, 1998.

[225] T. Yang, H.-X. Shi, Z.-T. Wang, and C.-H. Wang, "Hypolipidemic effects of andrographolide and neoandrographolide in mice and rats," Phytotherapy Research, vol. 27, no. 4, pp. 618623, 2013.
[226] C. Y. Zhang and B. Tan, "Hypotensive activity of aqueous extract of Andrographis paniculata in rats," Clinical and Experimental Pharmacology and Physiology, vol. 23, no. 8, pp. 675-678, 1996.

[227] Y. Zhang, J. Tang, and Y. Zhang, "Study of Andrographis paniculata extracts on antiplatelet aggregation and release reaction and its mechanism," Zhongguo Zhong Xi Yi Jie He Za Zhi, vol. 14, no. 1, pp. 28-30, 1994 (Chinese).

[228] A. M. Al-Attar, "Hypolipidemic effects of coenzyme Q10 in experimentally induced hypercholesterolemic model in female rats," The American Journal of Pharmacology and Toxicology, vol. 5, no. 1, pp. 14-23, 2010.

[229] M. Briel, I. Ferreira-Gonzalez, J. J. You et al., "Association between change in high density lipoprotein cholesterol and cardiovascular disease morbidity and mortality: systematic review and meta-regression analysis," British Medical Journal, vol. 338, article b92, 2009.

[230] J. Stamler, M. L. Daviglus, D. B. Garside, A. R. Dyer, P. Greenland, and J. D. Neaton, "Relationship of baseline serum cholesterol levels in 3 large cohorts of younger men to longterm coronary, cardiovascular, and all-cause mortality and to longevity," Journal of the American Medical Association, vol. 284, no. 3, pp. 311-318, 2000.

[231] J.-H. Chen, G. Hsiao, A.-R. Lee, C.-C. Wu, and M.-H. Yen, "Andrographolide suppresses endothelial cell apoptosis via activation of phosphatidyl inositol-3-kinase/Akt pathway," Biochemical Pharmacology, vol. 67, no. 7, pp. 1337-1345, 2004.

[232] M. S. Zoha, A. H. Hussain, and S. A. Choudhury, "Antifertility effect of andrographis paniculata in mice.," Bangladesh Medical Research Council Bulletin, vol. 15, no. 1, pp. 34-37, 1989.

[233] M. A. Akbarsha, B. Manivannan, K. S. Hamid, and B. Vijayan, "Antifertility effect of Andrographis paniculata (Nees) in male albino rat," Indian Journal of Experimental Biology, vol. 28, no. 5, pp. 421-426, 1990.

[234] S. Janarthanan, "Antifertility effects of andrographolide in rats," Journal of Ecobiology, vol. 2, no. 4, pp. 325-329, 1990.

[235] M. A. Akbarsha and B. Manivannan, "Biochemical changes in the testis and male accessory organs of albino rats on treatment with Andrographis paniculata Nees," Indian Journal of Comparative Animal Physiology, vol. 11, no. 2, pp. 103-108, 1993.

[236] R. Kamal, R. S. Gupta, and N. K. Lohiya, "Plants for male fertility regulation," Phytotherapy Research, vol. 17, no. 6, pp. 579-590, 2003.

[237] R. A. Burgos, E. E. Caballero, N. S. Sánchez, R. A. Schroeder, G. K. Wikman, and J. L. Hancke, "Testicular toxicity assesment of Andrographis paniculata dried extract in rats," Journal of Ethnopharmacology, vol. 58, no. 3, pp. 219-224, 1997.

[238] A. Mkrtchyan, V. Panosyan, A. Panossian, G. Wikman, and H. Wagner, "A phase I clinical study of Andrographis paniculata fixed combination Kan Jang versus ginseng and valerian on the semen quality of healthy male subjects," Phytomedicine, vol. 12, no. 6-7, pp. 403-409, 2005.

[239] J. Sattayasai, S. Srisuwan, T. Arkaravichien, and C. Aromdee, "Effects of andrographolide on sexual functions, vascular reactivity and serum testosterone level in rodents," Food and Chemical Toxicology, vol. 48, no. 7, pp. 1934-1938, 2010.

[240] J. J. Allan, M. P. Pore., M. Deepak, B. Murali, A. S. Mayachari., and A. Agarwal, "Reproductive and fertility effects of an extract of andrographis paniculata in male wistar rats," International Journal of Toxicology, vol. 28, no. 4, pp. 308-317, 2009.

[241] A. Panossian, A. Kochikian, E. Gabrielian et al., "Effect of Andrographis paniculata extract on progesterone in blood 
plasma of pregnant rats," Phytomedicine, vol. 6, no. 3, pp. 157$162,1999$.

[242] S. Balu, C. A. Boopathi, and V. Elango, "Antipyretic activities of some species of Andrographis wall," Ancient Science of Life, vol. 12, no. 3-4, pp. 399-402, 1993.

[243] K. Jarukamjorn, K. Don-in, C. Makejaruskul et al., "Impact of Andrographis paniculata crude extract on mouse hepatic cytochrome P450 enzymes," Journal of Ethnopharmacology, vol. 105, no. 3, pp. 464-467, 2006.

[244] C. V. Chandrasekaran, P. Thiyagarajan, K. Sundarajan et al., "Evaluation of the genotoxic potential and acute oral toxicity of standardized extract of Andrographis paniculata (KalmCold)," Food and Chemical Toxicology, vol. 47, no. 8, pp. 1892-1902, 2009.

[245] Y. Sharifuddin, E. M. Parry, and J. M. Parry, "The genotoxicity and cytotoxicity assessments of andrographolide in vitro," Food and Chemical Toxicology, vol. 50, no. 5, pp. 1393-1398, 2012.

[246] B. Kligler, C. Ulbricht, E. Basch et al., “Andrographis paniculata for the treatment of upper respiratory infection: a systematic review by the natural standard research collaboration," Explore: The Journal of Science and Healing, vol. 2, no. 1, pp. 25-29, 2006.

[247] R. M. Smith, "Before the injection-modern methods of sample preparation for separation techniques," Journal of Chromatography A, vol. 1000, no. 1-2, pp. 3-27, 2003.

[248] J. Azmir, I. S. M. Zaidul, M. M. Rahman et al., "Techniques for extraction of bioactive compounds from plant materials: a review," Journal of Food Engineering, vol. 117, no. 4, pp. 426-436, 2013.

[249] B. B. Li, B. Smith, and M. M. Hossain, "Extraction of phenolics from citrus peels: II. Enzyme-assisted extraction method," Separation and Purification Technology, vol. 48, no. 2, pp. 189196, 2006.

[250] L. Howard and N. Pandjaitan, "Pressurized liquid extraction of flavonoids from spinach," Journal of Food Science, vol. 73, no. 3, pp. C151-C157, 2008.

[251] M. S. Hossain, N. A. Ismail, and I. C. Phang, "Effect of salinity stress on morphology and physiology of Andtrographis paniculata," in Proceedings of the International Association for Plant Biotechnology Congress, Book of Abstracts, p. 204, Melbourne Convention and Exhibition Centre, Melbourne, Australia, August 2014.

[252] R. Verpoorte, R. van der Hejden, H. J. G. ten Hoopen, and J. Memelink, "Metabolic engineering of plant secondary metabolite pathways for the production of fine chemicals," Biotechnology Letters, vol. 21, no. 6, pp. 467-479, 1999.

[253] A. Wahid and A. Ghazanfar, "Possible involvement of some secondary metabolites in salt tolerance of sugarcane," Journal of Plant Physiology, vol. 163, no. 7, pp. 723-730, 2006.

[254] C. Olano, F. Lombó, C. Méndez, and J. A. Salas, "Improving production of bioactive secondary metabolites in actinomycetes by metabolic engineering," Metabolic Engineering, vol. 10, no. 5, pp. 281-292, 2008.

[255] Y.-P. Yan and Z.-Z. Wang, "Genetic transformation of the medicinal plant Salvia miltiorrhiza by Agrobacterium tumefaciens-mediated method," Plant Cell, Tissue and Organ Culture, vol. 88, no. 2, pp. 175-184, 2007.

[256] D. Talei, A. Valdiani, M. Maziah, S. R. Sagineedu, and M. S. Saad, "Analysis of the anticancer phytochemicals in Andrographis paniculata Nees. under salinity stress," BioMed Research International, vol. 2013, Article ID 319047, 11 pages, 2013. 

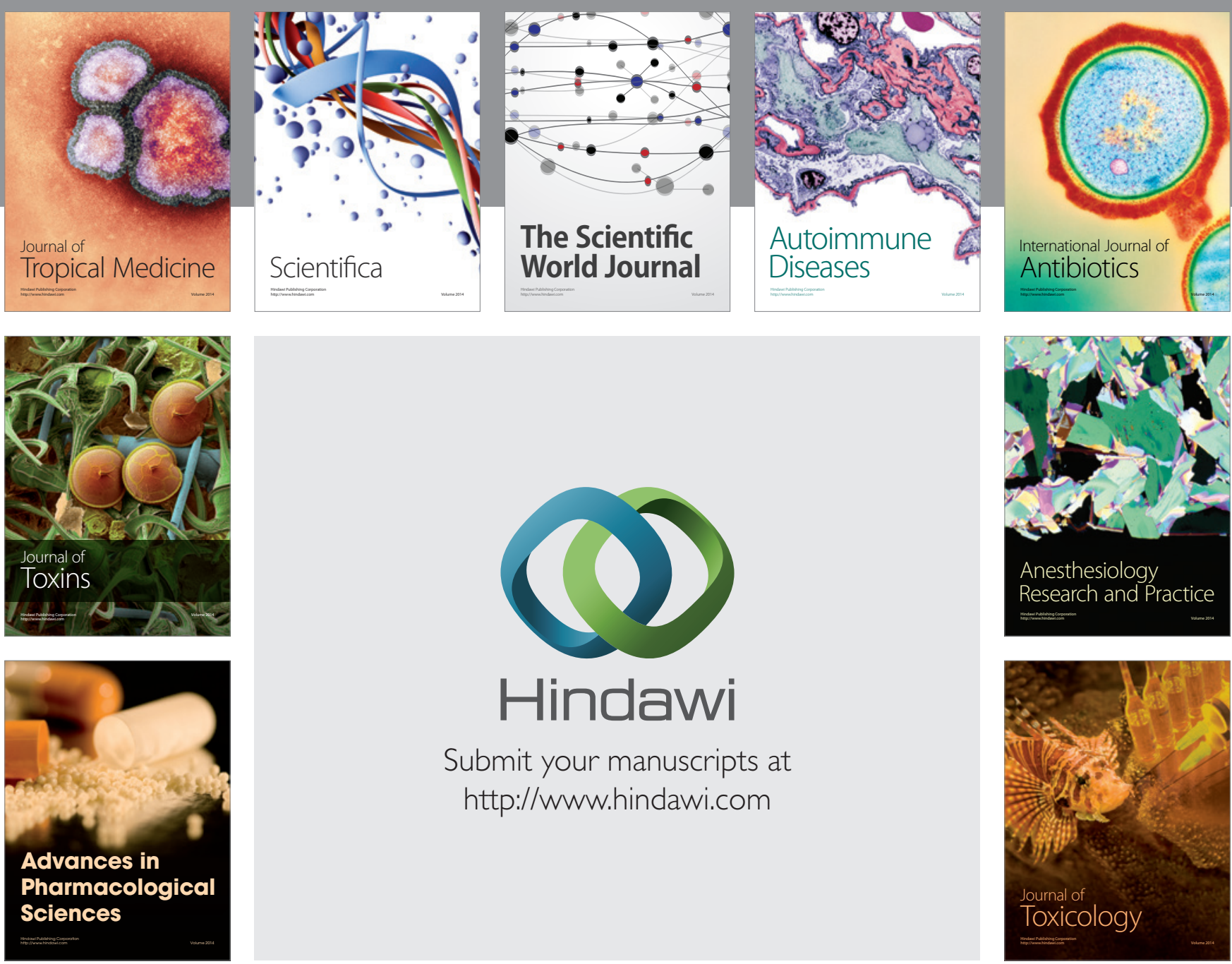

\section{Hindawi}

Submit your manuscripts at

http://www.hindawi.com
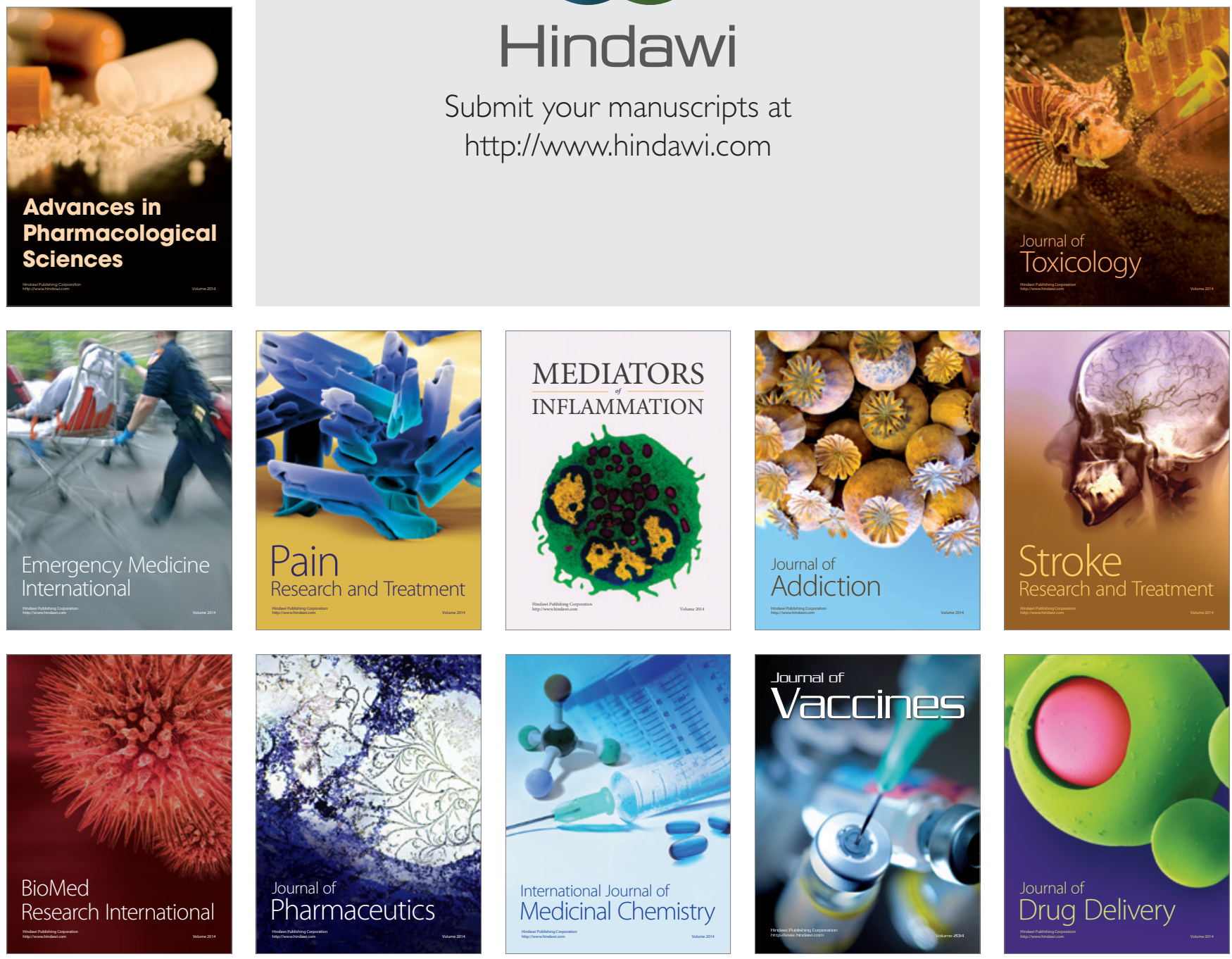